\title{
Rare, deep-water and similar: revision of Sibogasyrinx (Conoidea: Cochlespiridae)
}

\author{
Yuri I. KANTOR ${ }^{1, *} \&$ Nicolas PUILLANDRE ${ }^{2}$ \\ ${ }^{1}$ A.N. Severtsov Institute of Ecology and Evolution, Russian Academy of Sciences, \\ Leninski prospect 33, 119071 Moscow, Russian Federation. \\ 1,2 Institut Systématique Evolution Biodiversité (ISYEB), Muséum national d'histoire naturelle, CNRS, \\ Sorbonne Université, EPHE, Université des Antilles, 57 rue Cuvier, 75005 Paris, France. \\ *Corresponding author: kantor.yuri1956@gmail.com \\ ${ }^{2}$ Email: puillandre@mnhn.fr \\ ${ }^{1}$ urn:1sid:zoobank.org:author:48F89A50-4CAC-4143-9D8B-73BA82735EC9 \\ ${ }^{2}$ urn:1sid:zoobank.org:author:00565F2A-C170-48A1-AAD9-16559C536E4F
}

\begin{abstract}
The genus Sibogasyrinx has to date included only four species of rare deep-water Conoidea, each known from few specimens. In shell characters it strongly resembles three distantly-related genera, two of which, Comitas and Leucosyrinx, belong to a different family, the Pseudomelatomidae. A molecular phylogenetic analysis of a large amount of material of Conoidea has revealed the existence of much additional undescribed diversity within Sibogasyrinx from the central Indo-Pacific and temperate Northern Pacific. Based on partial sequences of the mitochondrial cox 1 gene and morphological characters of 54 specimens, 10 species hypotheses are proposed, of which six are described as new species: S. subula sp. nov., S. lolae sp. nov., S. maximei sp. nov., S. clausura sp. nov., S. pagodiformis sp. nov. and $S$. elbakyanae Kantor, Puillandre \& Bouchet sp. nov. One of the previously described species was absent in our material. Most of the new species are very similar and are compared to Leucosyrinx spp. Species of Sibogasyrinx are unique among Conoidea on account of the high intrageneric variability in radular morphology. Three distinct radula types are found within Sibogasyrinx, two of which are confined to highly supported subclades.
\end{abstract}

Keywords. Sibogasyrinx pyramidalis species complex, deep-water Conoidea, cox-1, integrative taxonomy, new species.

Kantor Yu.I. \& Puillandre N. 2021. Rare, deep-water and similar: revision of Sibogasyrinx (Conoidea: Cochlespiridae). European Journal of Taxonomy 773: 19-60. https://doi.org/10.5852/ejt.2021.773.1509

\section{Introduction}

The superfamily Conoidea is well known for high levels of homoplasy in shell form. Molecular studies have revealed that very similar or nearly indistinguishable shell morphologies are found in distantly related lineages (Puillandre et al. 2011; Abdelkrim et al. 2018), thus rendering the attribution of species to genus and even family questionable, when based on shell characters alone. 
Particularly striking examples of such homoplastic shells are found in the genera Comitas Finlay, 1926, Leucosyrinx Dall, 1889, Sibogasyrinx Powell, 1969 and, to some extent, Comispira Kantor, Fedosov \& Puillandre, 2018, all of which possess rather similar fusiform shells with a long siphonal canal and axial ribs or nodules on a more or less angular shoulder. Sibogasyrinx was originally established as a subgenus of Leucosyrinx, at that time assigned to the Cochlespiridae (Powell 1966; Taylor et al. 1993). However, molecular data demonstrate that Leucosyrinx constitutes a sister group to the Pseudomelatomidae, albeit with low support, while Sibogasyrinx is clearly referable to the Cochlespiridae (Puillandre et al. 2011; Abdelkrim et al. 2018). Furthermore, species of Sibogasyrinx are characterized by a radula typical of Cochlespiridae - with paired marginal and well-defined central teeth, in contrast to Leucosyrinx spp. which possess only marginal teeth (Bouchet et al. 2011). Both radula type and phylogenetic analyses (Bouchet et al. 2011; Puillandre et al. 2011; Abdelkrim et al. 2018) confidently placed Comitas in the Pseudomelatomidae. Finally, the recently described Comispira is clearly referable to the Cochlespiridae, both on anatomical and molecular grounds.

The taxonomy and morphology of these genera were treated in detail by Kantor et al. (2018); however, although they can be reliably distinguished by the morphology of the radula, most of the species have never been examined in this respect. Consequently, the generic placement of the anatomically unknown species relies in most cases on shell characters only, even though generic diagnoses based on conchological features are still lacking. For example, Sibogasyrinx originally included two species with "peripheral angle right down at the lower suture" (Powell 1969: 343). Later it was found that this character is inconsistent and in Sibogasyrinx sangeri Kantor et al., 2018 the angulation may be situated at mid-whorl (Kantor et al. 2018). Finally, many species are known from a very limited number of specimens, and their interspecific and intraspecific variability has not been evaluated.

A consequence of this taxonomic imprecision is that the generic placement of species is often doubtful. Most species are currently attributed to the pseudomelatomid genera Leucosyrinx and Comitas, with 26 and 53 valid Recent species, respectively (MolluscaBase), while the cochlespirid genera Comispira and Sibogasyrinx only include two and three species, respectively. Furthermore, while DNA sequences of only seven species of Leucosyrinx (four undescribed), three of Comitas (two undescribed), two of Comispira and two of Sibogasyrinx are available in GenBank, molecular data from Indo-Pacific material in the Muséum national d'histoire naturelle (MNHN) revealed the existence of numerous undescribed species of Sibogasyrinx, including several that cluster with the type species, S. pyramidalis (Schepman, 1913). The aim of this publication is the clarification of the diagnosis of Sibogasyrinx and a taxonomic revision of the genus based on molecular and morphological data.

\section{Material and methods}

\section{Sampling}

Samples were collected during several expeditions of the MNHN (expeditions.mnhn.fr): DongSha 2014 and NanHai 2014 in the South China Sea, AURORA 2007 and PANGLAO 2005 in the Philippines, SALOMON 2 and SALOMONBOA 3 in the Solomon Islands, BIOPAPUA, KAVIENG 2014, MADE EP and PAPUA NIUGINI in Papua New Guinea, BOA1 and SANTO 2006 in Vanuatu, EXBODI, KANADEEP and TERRASSES in New Caledonia, EBISCO in the Chesterfield Islands, MIRIKY in Madagascar and GUYANE 2014 in French Guiana. Full details on the stations of these expeditions, including dates, are available at the above-mentioned website. One additional sample was collected in New South Wales, Australia, during the IN2017_V03 expedition on R/V Investigator. Specimens processed before 2012 were anaesthetized using an isotonic solution of $\mathrm{MgCl}_{2}$ before fixation in $96 \%$ ethanol. Specimens processed after 2012 were microwaved and fixed in 96\% ethanol (Galindo et al. 2014). The samples are recorded in the BOLD database and the sequences have been deposited in GenBank (Table 1). 


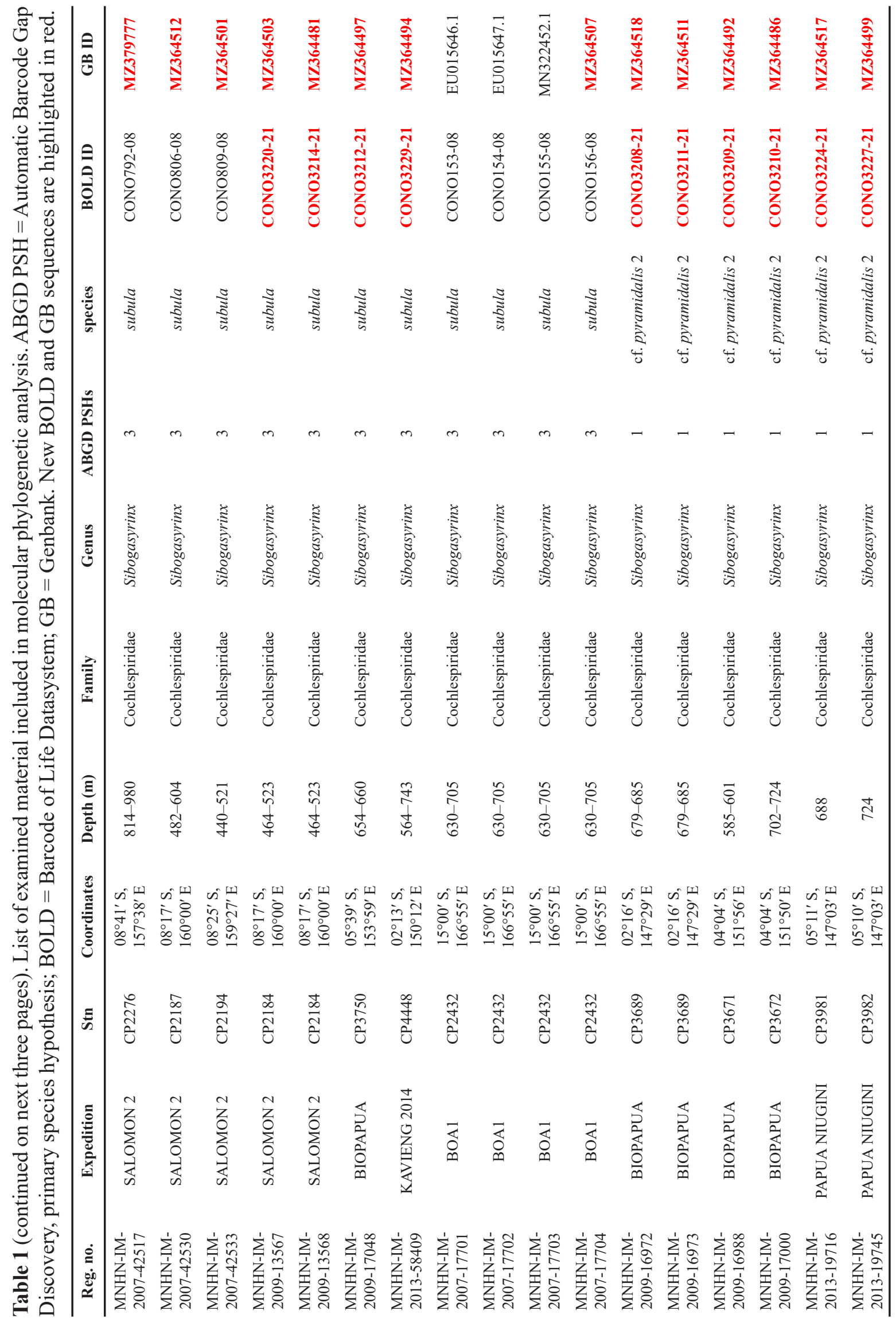




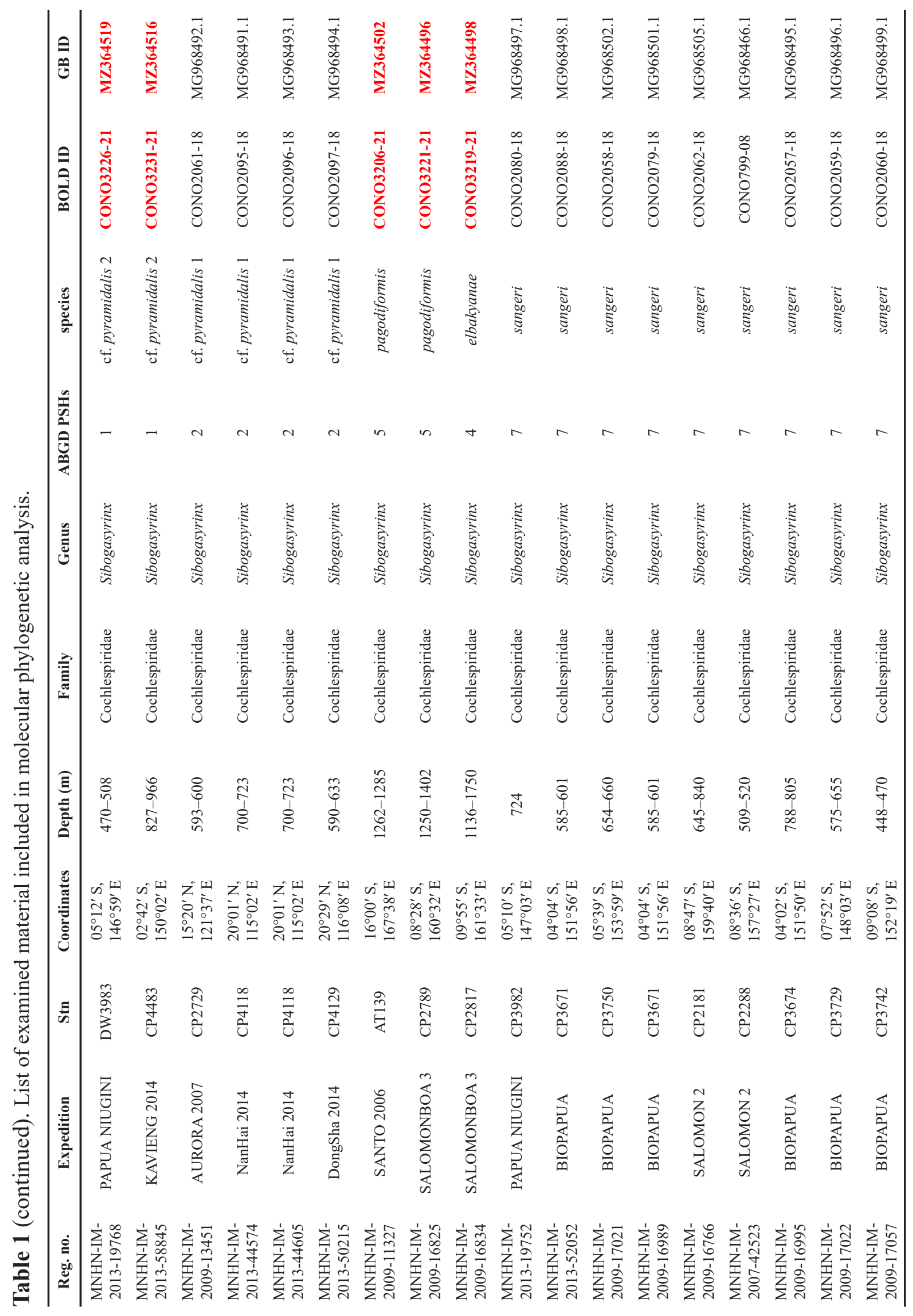




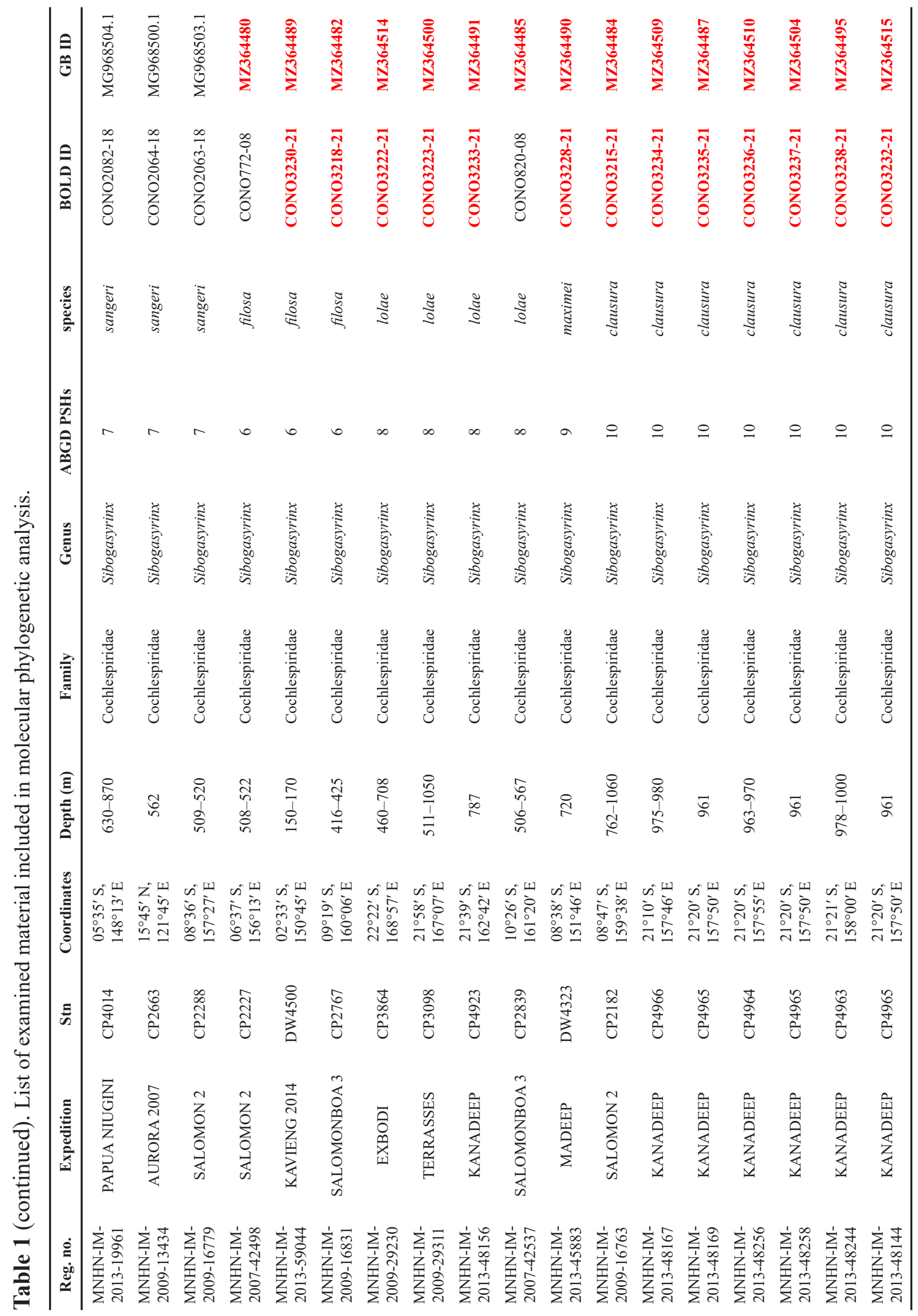




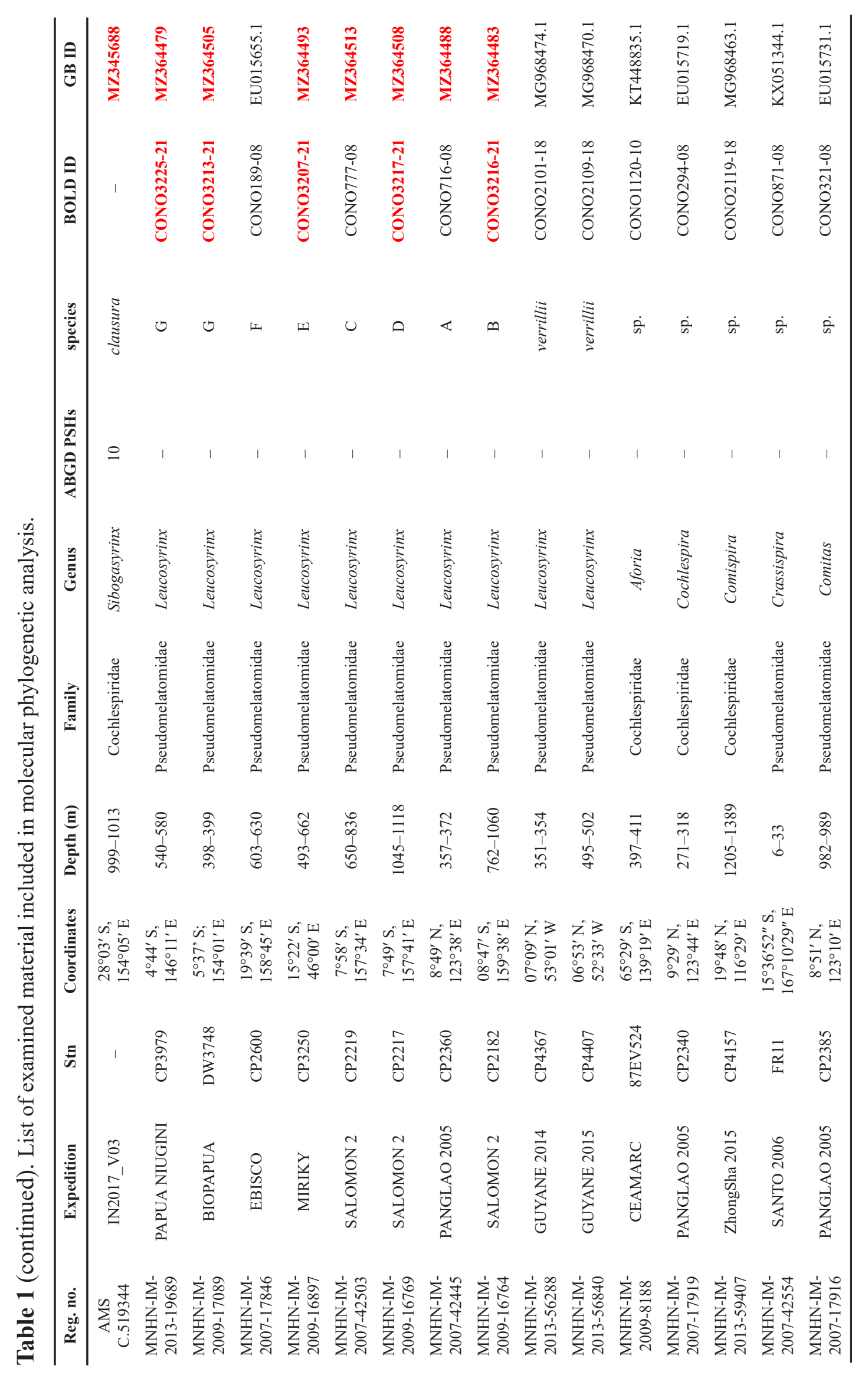




\section{DNA sequencing}

DNA was extracted using the Epmotion 5075 robot (Eppendorf), following the manufacturer's recommendations. The barcode fragment $(658 \mathrm{bp})$ of the mitochondrial coxl gene was amplified using the universal primers LCO1490/HCO2198 (Folmer et al. 1994). Polymerase chain reactions (PCRs) were performed using a previously well-established protocol (Puillandre et al. 2017). The PCR products were purified and sequenced by the Eurofins sequencing facility.

\section{Species delimitation}

The cox 1 sequences were aligned manually (no gaps were inferred). The Automatic Barcode Gap Discovery (ABGD; Puillandre et al. 2012a) and Assemble Species by Automatic Partitioning (ASAP; Puillandre et al. 2021) methods were used to propose primary species hypotheses (PSH), using the web versions (https://bioinfo.mnhn.fr/abi/public/abgd/abgdweb.html and https://bioinfo.mnhn.fr/abi/public/asap/) with default parameters. Both methods use genetic distances only. ABDG automatically detects the gap (the so-called 'barcode gap') between intra- and interspecific distances, which is then used to propose species hypotheses. ASAP screens all the genetic distances from the lowest to the highest and merges sequences into 'groups' that are successively further merged until all sequences form a single group. At each merging step, the partition is evaluated and given a score. At the end of the analyses, the 10 partitions with the lowest scores are provided (the lower the ASAP-score, the better the partition).

The robustness of the PSHs proposed by ABGD and ASAP was then evaluated by checking whether they correspond to highly supported clades, whether they are conchologically and anatomically diagnosable, and whether they are geographically and/or bathymetrically isolated, and in so doing they were converted into secondary species hypotheses (SSH), following the methodology described in Puillandre et al. (2012b).

\section{Phylogenetic analyses}

Phylogenetic trees were reconstructed using the cox 1 alignment containing the Sibogasyrinx sequences, plus Leucosyrinx, Comitas and Comispira sequences for comparison, and outgroups from the respective families of the four genera (Cochlespiridae and Pseudomelatomidae) (Table 1). Maximum Likelihood (ML) and Bayesian Approach (BA) were used to infer phylogenetic trees. ML was performed using the IQ-Tree webserver (http://iqtree.cibiv.univie.ac.at/) (Trifinopoulos et al. 2016), and robustness of the tree was estimated using ultrafast bootstrapping (1000 replicates) (Minh et al. 2013). BA was performed using MrBayes 3.2. (Ronquist et al. 2012), as implemented on the Cipres Science Gateway (MrBayes ver. 3.2.2 on XSEDE; http://www.phylo.org/portal2), with two parallel analyses consisting each of 8 Markov chains for 30000000 generations with 5 swaps at each generation, a sampling frequency of one tree each 10000 generations, a chain temperature of 0.02 and the parameters of the substitution model estimated during the analysis. Convergence of each analysis was evaluated using Tracer ver. 1.4.1 (Rambaut et al. 2014) by checking that ESS values all exceeded 200, and a consensus tree was reconstructed after removing trees from the burn-in phase (first $25 \%$ of the trees). For the ML, the best substitution model for each codon position was estimated during the analysis. For the BA, a substitution model with six substitution categories, a gamma-distributed rate variation across sites approximated in four discrete categories and a proportion of invariable sites was used for each codon position independently.

\section{Morphological studies}

Protoconchs were measured in standard position and the number of whorls counted according to Bouchet \& Kantor (2004). Foregut anatomy was examined by dissections. Radulae were prepared by standard methods (Kantor \& Puillandre 2012) and examined by scanning electron microscopy (TeScan TS5130MM) at the Institute of Ecology and Evolution of the Russian Academy of Sciences (IEE RAS). 


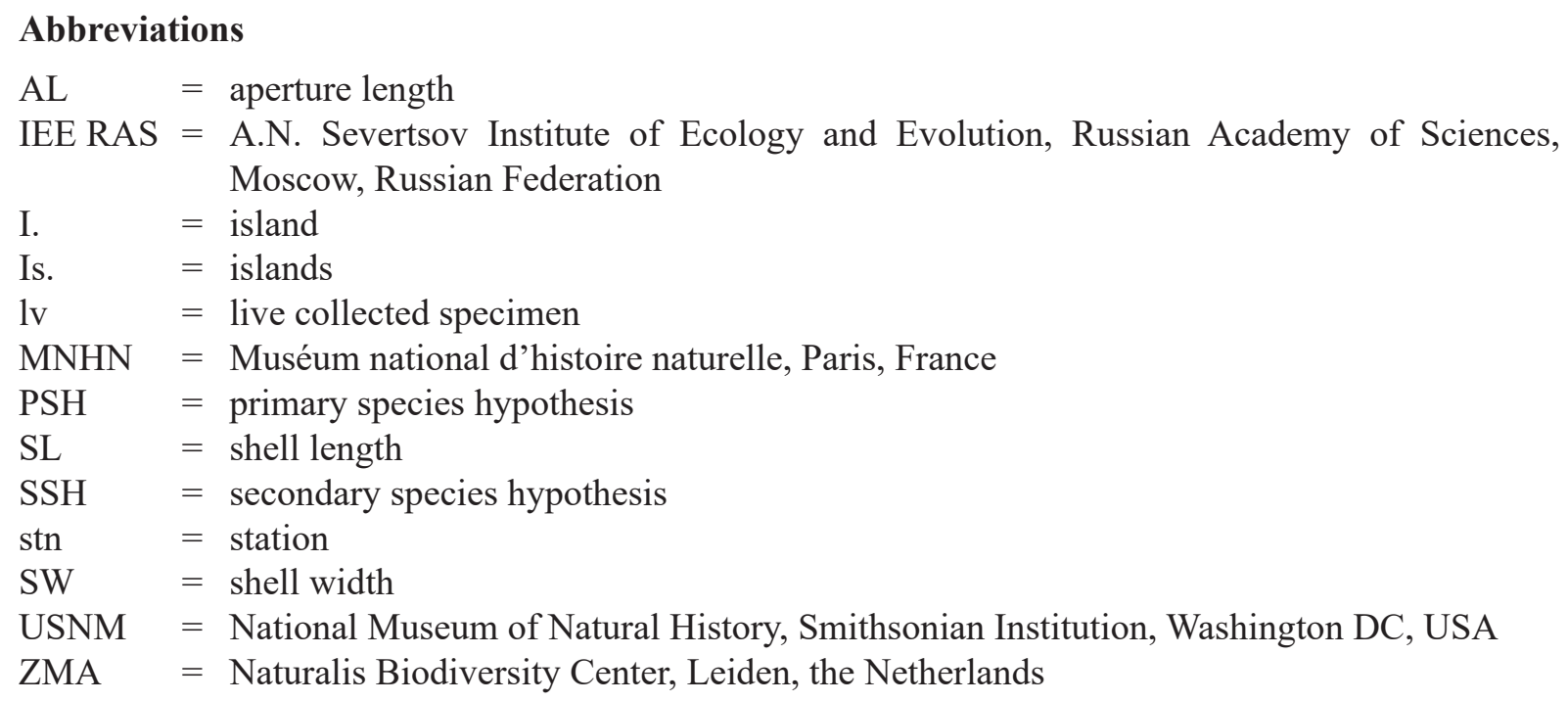

\section{Results}

\section{Phylogenetic analysis}

\section{ABGD and ASAP partitions}

ABGD consistently returned a partition with 10 PSHs, numbered from PSH 1 to PSH 10 (Fig. 1). The best ASAP partition includes 9 PSHs, with the ABGD PSHs 4 and 5 grouped into a single PSH. The second best ASAP partition includes 10 PSHs, identical to the ABGD PSHs. The third best ASAP partition includes 11 PSHs, splitting the ABGD PSH 2 into two PSHs, one including the single specimen from the Philippines, the other including the three specimens from Taiwan. The remaining ASAP partitions have a much higher score and will not be discussed further.

\section{From PSHs to SSHs}

All the ABGD PSHs are morphologically distinct, although PSHs 1 and 2 exhibit considerable similarity (see below-Taxonomy). All the studied Sibogasyrinx have a protoconch suggestive of non-planktotrophic development, thus suggesting limited dispersal abilities. All the ABGD PSHs including more than one sample correspond to supported (Posterior Probabilities PP $>0.95$ and Bootstraps BS $>90$ ) or highly supported ( $\mathrm{PP}>0.98$ and BS $>95$ ) clades. Three main lineages can be recognized, all highly supported. The first one includes PSH 1, 2 and 3, of which PSH 1 and 2 are morphologically very similar; the former is from Papua New Guinea, the latter from Taiwan and the Philippines. They are thus allopatric, but they are not sister taxa, PSH 2 being sister to the morphologically distinct PSH 3 from Papua New Guinea (together with the PSH 1, but not from the same station), but also occurring in the Solomon Islands and Vanuatu. These three PSHs have overlapping bathymetric distributions, between 500 and $1000 \mathrm{~m}$ deep (Fig. 2). Because of their cox-1 distinctiveness and the morphological differentiation between the two most closely related PSHs, we convert these 3 PSHs into 3 SSHs. The split of PSH 2 into two PSHs in the third ASAP partition is interpreted as resulting from genetic distances between allopatric populations within a single species, potentially linked to the limited dispersal abilities of the species.

The second main lineage includes PSH 4 and 5, represented by only one and two samples, respectively. Both are found at similar depths (1200-1700 m), thus deeper than the PSH from the first lineage, and both are found in the Solomon Islands (PSH 5 also occurring in Vanuatu) (Fig. 2). They are easily distinguished morphologically, and we convert these two PSHs into 2 SSHs, thus contradicting the hypothesis proposed in the first partition of ASAP. 
The third main lineage includes five PSHs (6 to 10). Except for PSH 9, represented by a single specimen, all these PSHs are found in at least two localities, and all of them have at least one representative from the Solomon Islands, but never from the same station (although sometimes from geographically very close stations). Three PSHs (6, 7 and 9) are found in Papua New Guinea, and again never at the same station. PSHs 8 and 10 are both present in New Caledonia, likewise from different stations. PSH 6 is found in relatively shallow water (between 150 and $500 \mathrm{~m}$ ), whereas PSHs 7, 8 and 9 are found at depths between 500 and $800 \mathrm{~m}$, and PSH 10 is found even deeper, between 900 and $1000 \mathrm{~m}$. In contrast

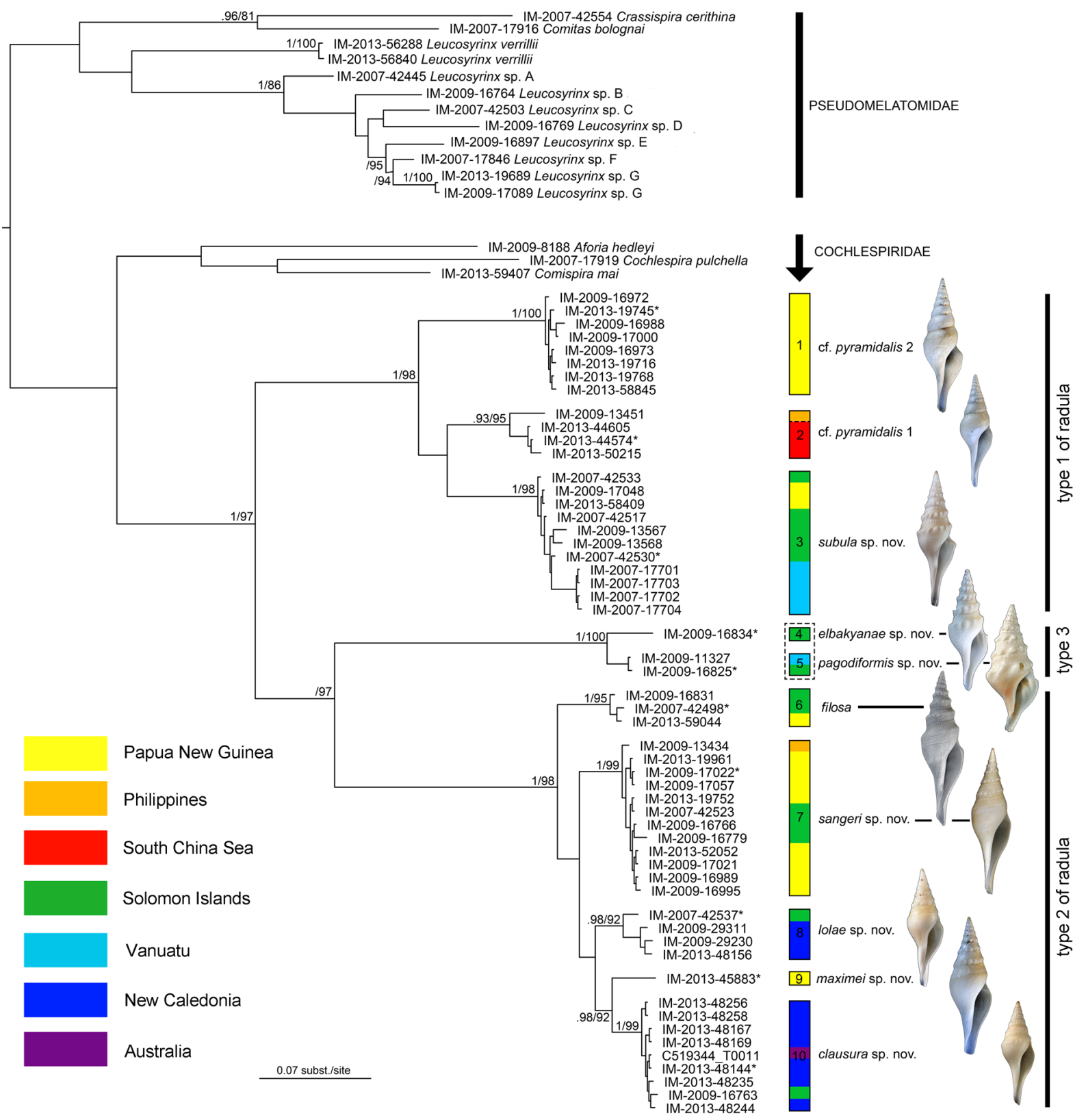

Fig. 1. Bayesian phylogenetic tree obtained with the coxl dataset. Posterior probabilities $(>0.95)$ and bootstraps (>90) are shown for each node. The boxes in front of the lineages of Sibogasyrinx Powell, 1969 represent the ABGD PSHs, numbered from 1 to 10. Alternative PSH partitions obtained in the second and third-best ASAP partitions are shown with dashed lines. The colors refer to the locality; $*=$ illustrated shells. 
to the first two main lineages, the PSHs in the third main lineage tend to be bathymetrically structured, with the shallowest species sister to the four others, and the three intermediate ones in paraphyly and including the deepest one. Finally, diagnostic morphological characters have been found to distinguish these five PSHs. The cox-1 and morphological distinctiveness together with sympatric distributions sometimes associated with bathymetric partitions, potentially correlated to ecological distinctiveness, are interpreted as arguments supporting the conversion of these five PSHs into SSHs.

The three main lineages recovered (PSH 1-3/PSH 4-5/PSH 6-10), although not distinguishable by shell characters, are characterized by different radula morphologies (see Taxonomy section below; Fig. 1). Furthermore, the cox-1 distances among these lineages are similar to the distances between genera of Cochlespiridae. For these reasons, they could have been recognized as (sub)genera. However,

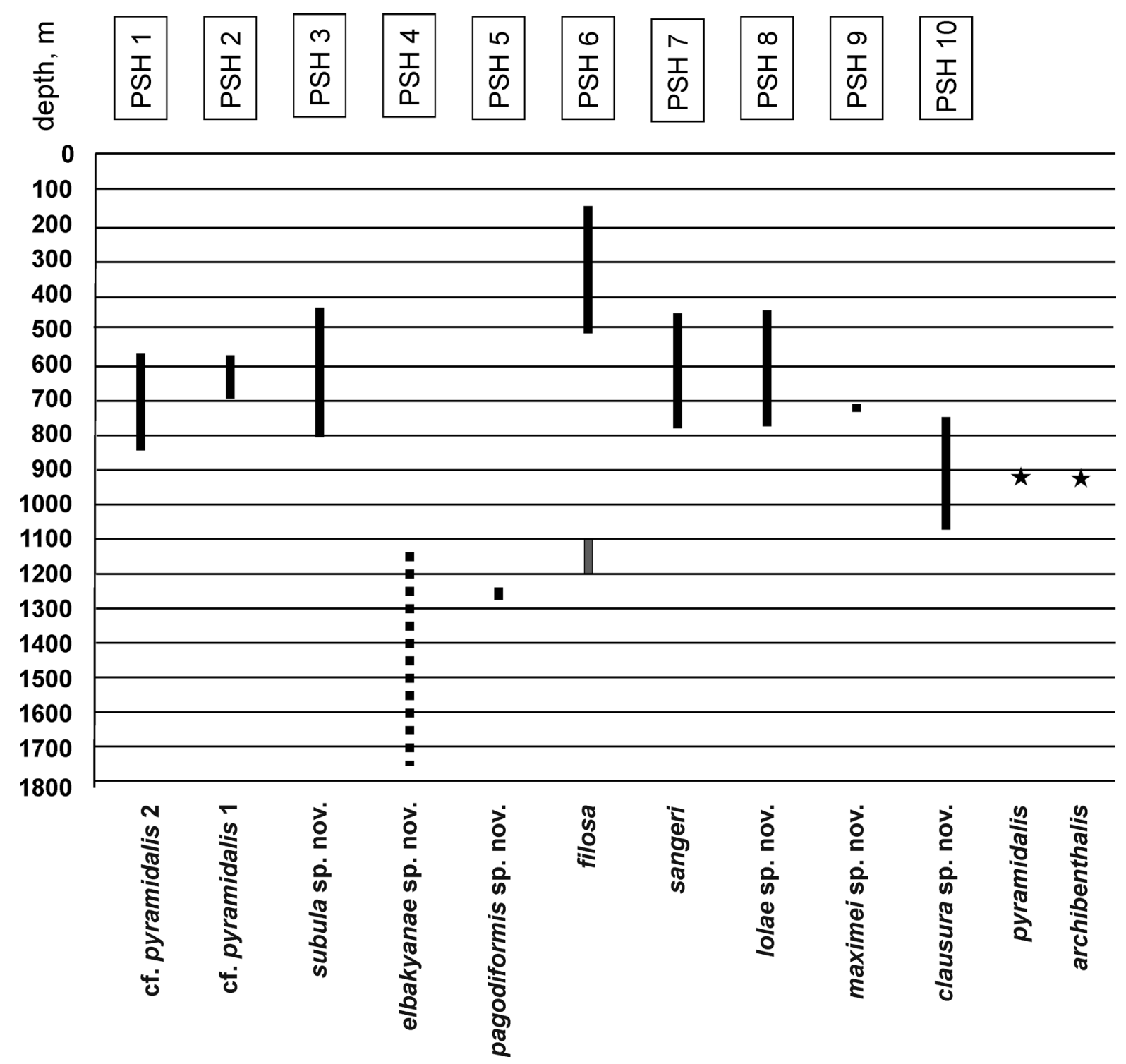

Fig. 2. Bathymetric ranges of species of Sibogasyrinx Powell, 1969. The dashed bar for PSH 4 (S. elbakyanae sp. nov.) marks the range of the trawl haul in which a single specimen was collected. The grey bar for PSH 6 (S. filosa Ardovini, 2021) indicates the depths of occurrence of the type material. Stars indicate the depths of collection of the holotypes of non-sequenced species. 
because of their morphological similarity, and, more importantly, because of the lack of DNA sequence data for the type species of the genus (see Taxonomy section below), attributing the name Sybogasyrinx to any of the three lineages (and thus new names for the two others) would be untimely, and we thus abstain from naming them.

\section{From SSH to named species}

Both PSH 1 and 2 resemble the type of $S$. pyramidalis and we refer to them as $S$. cf. pyramidalis 1 and S. cf. pyramidalis 2 (see below - Taxonomy - for more discussion). The specimens of PSH 6 are very similar to the type material of $S$. filosa Ardovini, 2021 and we apply this name to it. PSH 7 contains the holotype of S. sangeri, and this name has thus been applied to this PSH. We were not able either to link the name archibenthalis (Powell, 1969) or any names proposed in other genera to any of the remaining PSHs (PSHs 3-5 and 8-10), and they are thus described as new species: S. subula sp. nov. (= PSH 3), S. elbakyanae sp. nov. (= PSH 4), S. pagodiformis sp. nov. (= PSH 5), S. lolae sp. nov. (= PSH 8), S. maximei sp. nov. (= PSH 9) and S. clausura sp. nov. (= PSH 10). Sibogasyrinx archibenthalis is thus the only species of the genus not represented in the molecular phylogeny.

For comparative purposes, we included several specimens of the distantly related genus Leucosyrinx that bear a strong conchological resemblance to the species of Sibogasyrinx treated herein. All but one, L. verrillii (Dall, 1881) (the type species of the genus), represent still unnamed species that are marked on the tree as Leucosyrinx sp. A to Leucosyrinx sp. G (Fig. 1). The included specimens represent a subsample of the sequenced material for the corresponding species and therefore we abstain from describing the new species pending a general revision of the genus.

\section{Taxonomy}

Class Gastropoda Cuvier, 1795

Subclass Caenogastropoda Cox, 1960

Order Neogastropoda Wenz, 1938

Superfamily Conoidea Fleming, 1822

Family Cochlespiridae Powell, 1942

Genus Sibogasyrinx Powell, 1969

Leucosyrinx (Sibogasyrinx) Powell, 1969: 343.

\section{Type species}

Surcula pyramidalis Schepman, 1913 (original designation).

\section{Diagnosis}

Shell small to large, adult length from 27 to $65 \mathrm{~mm}$, narrowly fusiform, rarely pagodiform, with concave to nearly flat subsutural ramp. Spiral sculpture variously developed, always present below shoulder, comprising narrow, close-set cords, often also on subsutural ramp, Shoulder with a row of strong nodules, often obsolete on last whorl.

Venom gland does not pass through nerve ring and opens into oesophagus within or posterior to nerve ring. Radula usually with central tooth, absent in one species, marginal tooth morphology variable, folded longitudinally. 
Sibogasyrinx pyramidalis (Schepman, 1913) complex

Sibogasyrinx pyramidalis (Schepman, 1913)

Fig. 3H-I

Surcula pyramidalis Schepman, 1913: 423, pl. 27, fig. 10a-b.

Leucosyrinx (Sibogasyrinx) pyramidalis - Powell 1969: 343 (23-411), pl. 264 figs 1-5. — Shuto 1970:

171, pl. 11 figs 10-13. - Medinskaya 1999: 176-177, figs 3, 16d-e.

Sibogasyrinx pyramidalis - Kantor et al. 2018: 57-58, figs 5e-n, 6c-d.

\section{Material examined}

\section{Holotype}

TIMOR SEA • $10^{\circ} 48.6^{\prime} \mathrm{S}, 123^{\circ} 23.1^{\prime}$ E; depth 918 m; ZMA.MOLL.136836.

\section{Remarks}

Kantor et al. (2018) provided illustrations of shells and radulae of sequenced specimens of what they considered to be $S$. pyramidalis. The specimens studied were collected off Luzon Island (Philippines) and in the central South China Sea (= PSH 2, S. cf. pyramidalis 1). The shell outline of these specimens of this generally variable species matched the illustration of the holotype, which was not examined. The present molecular analysis revealed that there are two molecularly distinct but morphologically cryptic species that match the description and illustrations of the holotype of $S$. pyramidalis (Schepman 1913: fig. 10a-b; Shuto 1970: pl. 11, figs 10-13; Fig. 3H-I herein). The second species, not discussed in Kantor et al. (2018), was collected in the Bismarck Sea and also displays significant shell variability (= PSH 1, S. cf. pyramidalis 2). The geographic ranges of these two PSHs do not include the type locality of S. pyramidalis (Timor Sea, Pulau Rote Island). There are two possible explanations for this: one of our species represents the true S. pyramidalis, or S. pyramidalis is a third species and both of ours are new to science. Unfortunately, this can only be resolved by sequencing topotypic material from the Timor Sea. In order to not add to the taxonomic ambiguity, we presently refrain from taking any taxonomic decision, but for the sake of convenience refer here to our molecular species as $S$. cf. pyramidalis 1 (= S. pyramidalis sensu Kantor et al. 2018) and S. cf. pyramidalis 2.

Medinskaya (1999: fig. 16d-e) illustrated the radula of a specimen from Indonesia (Tanimbar I., $08^{\circ} 36^{\prime} \mathrm{S}, 131^{\circ} 33^{\prime} \mathrm{E}, 699-676 \mathrm{~m}$ ) collected close to the type locality. Unfortunately, the shell was not illustrated and the identification of the specimen cannot be confirmed. Its radula is identical to that of S. cf. pyramidalis 1 and $S$. cf. pyramidalis 2 (Kantor et al. 2018: figs 5c-d, 6a-b; Fig. 4A-D herein).

Sibogasyrinx cf. pyramidalis (Schepman, 1913) 1 (= PSH 2)

Figs $3 \mathrm{~A}-\mathrm{G}, 4 \mathrm{~A}-\mathrm{B}$

Material examined (all sequenced)

PHILIPPINES • 1 lv; $15^{\circ} 20^{\prime} \mathrm{N}, 121^{\circ} 37^{\prime} \mathrm{E}$; depth 593-600 m; AURORA 2007, stn CP2729; MNHNIM-2009-13451.

SOUTH CHINA SEA 22 lv; $20^{\circ} 01^{\prime} \mathrm{N}, 115^{\circ} 02^{\prime} \mathrm{E}$; depth 700-723 m; NanHai 2014, stn CP4118; MNHNIM-2013-44574, MNHN-IM-2013-44605 • 1 lv; 20²9' N, 11608' E; depth 590-633 m; DongSha 2014, stn CP4129; MNHN-IM-2013-50215.

\section{Description}

Measurements (largest specimen). SL $65.2 \mathrm{~mm}$, AL (with canal) $35.1 \mathrm{~mm}$, AL (without canal) $21.0 \mathrm{~mm}$, SW $18.5 \mathrm{~mm}$. 


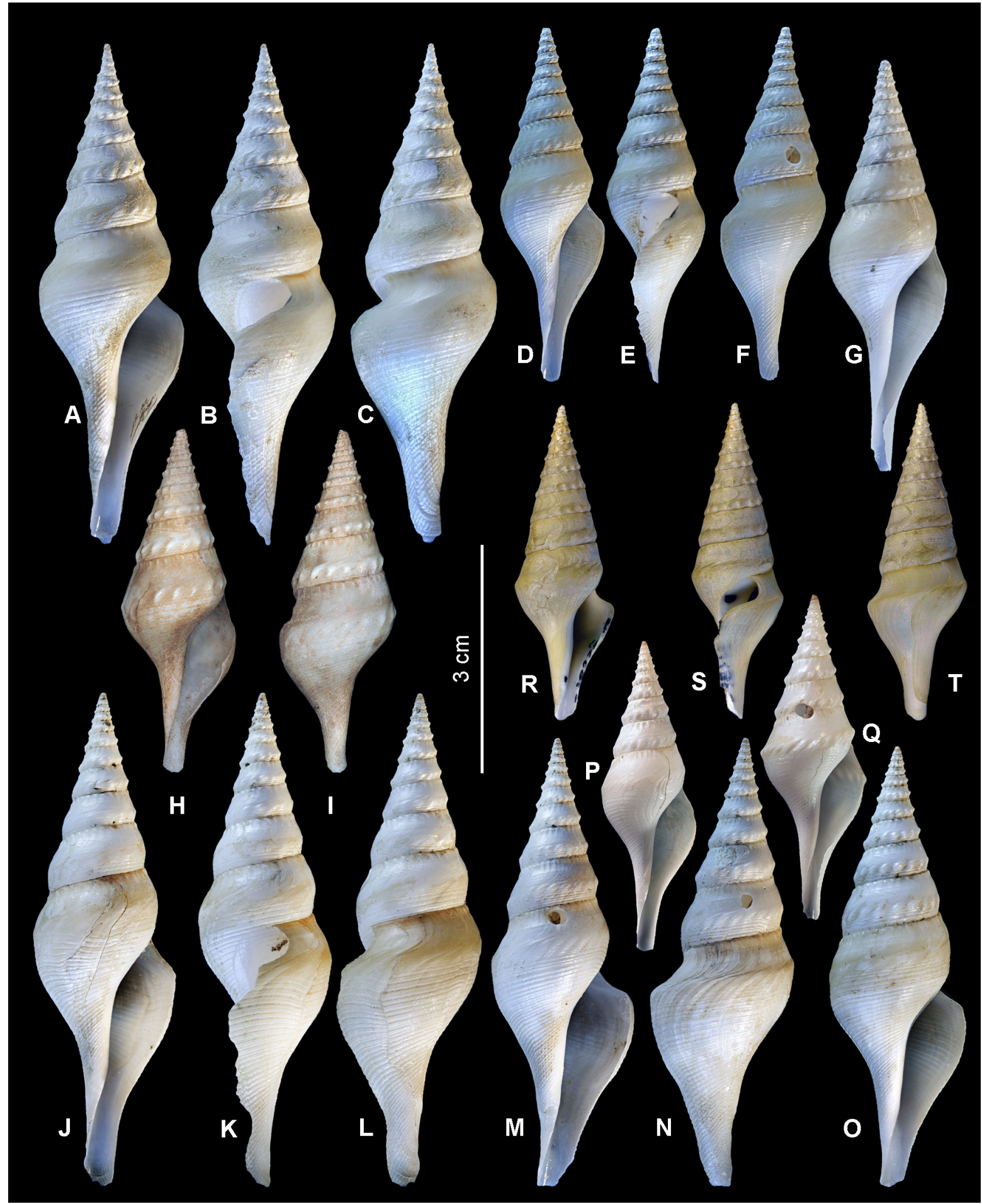

Fig. 3. Sibogasyrinx pyramidalis (Schepman, 1913) complex. A-G. Sibogasyrinx cf. pyramidalis 1. A-C. South China Sea, MNHN-IM-2013-44605, SL $65.2 \mathrm{~mm}$. D-F. Philippines, MNHNIM-2009-13451, SL 46.8 mm. G. South China Sea, MNHN-IM-2013-44574, SL 53.9 mm. H-I. Surcula pyramidalis Schepman, 1913, holotype, ZMA.MOLL.136836, SL 45 mm (photos by K. Hasegawa, copyright Naturalis, Leiden). J-Q. Sibogasyrinx cf. pyramidalis 2, Papua New Guinea. J-L. MNHNIM-2013-19745, SL 65.2 mm. M-O. MNHN-IM-2009-17000, SL 59.2 mm. P. MNHN-IM-2009-16973, SL 41 mm. Q. MNHN-IM-2009-16988, SL 43 mm. R-T. Sibogasyrinx archibenthalis (Powell, 1969), holotype, USNM 238773, SL $41.8 \mathrm{~mm}$. All shells to same scale. 
SHELL. Moderately thick, strong except for fragile outer aperture lip, fusiform, with high spire and long, narrow, straight siphonal canal. Protoconch small, globose, of about 1.5 strongly convex, microshagreened whorls, eroded or missing in all specimens. Early teleoconch whorls weakly to moderately angular at shoulder. Largest available specimen (SL $65.2 \mathrm{~mm}$ ) of 10.3 teleoconch whorls. Suture shallowly impressed, subsutural ramp broad, weakly concave to flat. All teleoconch whorls with a subsutural row of nodules, corresponding in shape to upper parts of thickened growth lines. Nodules more distinct on upper whorls, increasing in number, up to 30 on penultimate whorl and 37 on last whorl in largest specimen. Subsutural ramp may be completely smooth, or sometimes with very weak spiral striation or dendritic lines. Shoulder with pronounced thickened and rounded nodules, reaching lower suture, weakly opisthocline on upper whorls and more strongly inclined and confluent with growth lines on lower whorls. Nodules evanesce on last and even penultimate whorls at SL over $50 \mathrm{~mm}$ and shoulder becomes evenly rounded; their number increase with size from 14-15 on upper whorls to 21-22 on lower whorls. Spiral sculpture of 3-6 moderately pronounced, closely spaced narrow cords on shoulder, crossing shoulder nodules on spire whorls. Last whorl below shoulder with 40-45 cords varying in width, their intervals $0.5-2$ times width of cords, also distinct on canal. Shell base gradually narrowing towards long, narrow, nearly straight siphonal canal. Aperture narrow, constricted posteriorly, with narrow and thin parietal callus, outer lip with rounded angle at shoulder, weakly convex below shoulder and weakly concave at transition to canal. Anal sinus moderately deep, subsutural, broadly arcuate, confluent with large forward extension of outer lip. Shell off-white with very light yellowish subsutural band, protoconch pale tan. Periostracum persists on part of shell, light yellowish.

ANATOMY. Foregut similar to that of Sibogasyrinx cf. pyramidalis 2 (see below), except for presence of a large oval accessory salivary gland, adjoining oesophagus, with rather thick duct, entering proboscis and following along its wall.

Radula ( $\mathrm{n}=2$; MNHN-IM-2009-13451, MNHN-IM-2013-50215). Comprising approximately 40 rows of teeth, 15 nascent, short, length ca $2.5 \mathrm{~mm}$ (15\% of AL without canal). Radula width up to $530 \mu \mathrm{m}$ (3.3\% of AL without canal). Central tooth with broad, subrectangular basal plate and anteriorly broadly concave, borders distinct and with narrow but rather long, sharply pointed cusp. Marginal teeth with strongly thickened posterior edges, folded longitudinally. When immature, teeth nearly flat with elevated posterior edge, on developing part of radular tooth folding clearly visible (on Fig. 4A not fully folded teeth are marked by white arrows), bringing posterior and anterior edges close together. During tooth maturation the edges, particularly posterior one, progressively thicken, so that fully formed tooth appears duplex (Fig. 4B).

\section{Distribution}

The confirmed distribution is the South China Sea and the Philippines Sea, at 590-700 m.

Sibogasyrinx cf. pyramidalis (Schepman, 1913) 2 (= PSH 1)

Figs $3 \mathrm{~J}-\mathrm{Q}, 4 \mathrm{C}-\mathrm{D}, 5$

Material examined (all sequenced)

PAPUA NEW GUINEA • 2 lv; off Manus I.; 02 ${ }^{\circ} 16^{\prime} \mathrm{S}, 147^{\circ} 29^{\prime} \mathrm{E}$; depth 679-685 m; BIOPAPUA, stn CP3689; MNHN-IM-2009-16972, MNHN-IM-2009-16973 • 1 lv; N of Rabaul; 0404' S, $151^{\circ} 56^{\prime}$ E; depth 585-601 m; BIOPAPUA, stn CP3671; MNHN-IM-2009-16988 • 1 1v; N of Rabaul; 0404' S, 151 ${ }^{\circ} 50^{\prime}$ E; depth 702-724 m; BIOPAPUA, stn CP3672; MNHN-IM-2009-17000 • 1 lv; Bismarck Sea, N of Long I.; 05 $11^{\prime} \mathrm{S}, 147^{\circ} 03^{\prime} \mathrm{E}$; depth 688 m; PAPUA NIUGINI, stn CP3981; MNHN-IM-2013-19716 • 1 lv; Bismarck Sea, N of Long I.; $05^{\circ} 10^{\prime} \mathrm{S}, 147^{\circ} 03^{\prime} \mathrm{E}$; depth $724 \mathrm{~m}$; PAPUA NIUGINI, stn CP3982; MNHN-IM-2013-19745 • 1 lv; Bismarck Sea, NW of Long I.; 05¹2' S, $146^{\circ} 59^{\prime}$ E; depth 470-508 m; 

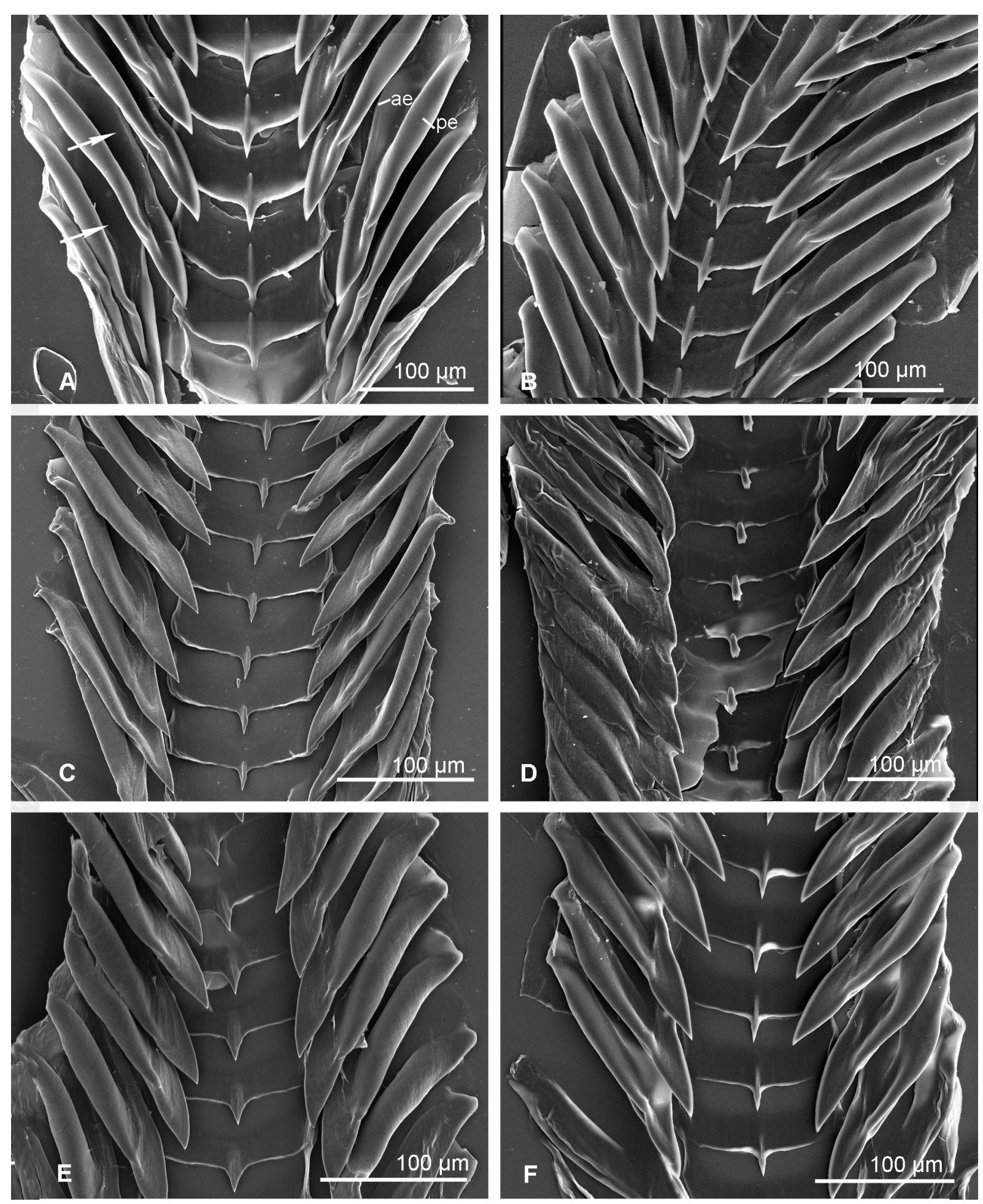

Fig. 4. Radulae of species of Sibogasyrinx Powell, 1969. A-B. S. cf. pyramidalis (Schepman, 1913) 1, MNHN-IM-2009-13451 (shell seen on Fig. 3D-F). A. Part of radula with marginal teeth not fully formed; white arrows indicate teeth that are not fully folded longitudinally (ae = anterior tooth edge; pe $=$ posterior tooth edge). B. Part of radula with fully formed marginal teeth. C. S. cf. pyramidalis 2, MNHN-IM-2009-16972. D. S. cf. pyramidalis 2, MNHN-IM-2009-17000 (shell seen on Fig. 3M-O). E. S. subula sp. nov., MNHN-IM-2007-17703. F. S. subula sp. nov., MNHN-IM-2009-13568 (shell seen on Fig. 6H-I). 
PAPUA NIUGINI, stn DW3983; MNHN-IM-2013-19768 • 1 lv; New Ireland, 0242' S, $150^{\circ} 02^{\prime}$ E; depth 827-966 m; KAVIENG 2014, stn CP4483; MNHN-IM-2013-58845.

\section{Description}

MeAsurements (largest specimen). SL $65.2 \mathrm{~mm}$, AL (with canal) $34.7 \mathrm{~mm}$, AL without canal $22.9 \mathrm{~mm}$, SW $18.0 \mathrm{~mm}$.

Shell. Extremely similar to that of Sibogasyrinx cf. pyramidalis 1 . The only slight difference is the larger number of spiral cords crossing the shoulder nodules. Penultimate whorl of $S$. cf. pyramidalis 1 with 5-6 cords (increasing with SL), 6-8 in S. cf. pyramidalis 2.

ANATOMY ( $\mathrm{n}=2$, MNHN-IM-2009-16972, MNHN-IM-2009-17000). Head with long, cylindrical tentacles, rounded on tips with closely spaced bases, eyes absent. One specimen (MNHN-IM-2009-17000) male, with long penis with obliquely truncated tip. Seminal papilla occupies entire tip and is surrounded by circular fold. Proboscis long, coiled, with broad conical base, occupied by large bulbous buccal mass, spanning posterior $1 / 4$ of proboscis and protruding backwards from proboscis. Proboscis sheath with very thin transparent walls. Remaining anterior part of proboscis narrow, gradually diminishing in diameter towards its tip. Proboscis retractors well defined, powerful and numerous, attached to posteriormost edge of rhynchodeum. Radular sac and short oval odontophore situated on right side of buccal mass, posterior to rear of proboscis. Oesophagus adjoining buccal mass slightly constricted and forming a moderately long loop before passing through nerve ring. Salivary glands irregularly shaped, covering dorsal portion of nerve ring. Accessory salivary gland not traced. Venom gland thick, long, strongly convoluted, opens dorsally into oesophagus, immediately posterior to nerve ring (Fig. 5B). Muscular bulb oval, of moderate size, situated to the right of oesophagus.

RADULA ( $\mathrm{n}=2$; MNHN-IM-2009-16972, MNHN-IM-2009-17000). Comprising approximately 40 rows of teeth, 15 nascent, short, length (measured only in MNHN-IM-2009-16972) ca $1.7 \mathrm{~mm}$ (14\% of AL without canal). Radula width up to $300 \mu \mathrm{m}$ ( $2.5 \%$ of AL without canal). Shape of teeth very similar to that of Sibogasyrinx cf. pyramidalis 1, central tooth has less rounded posterior margin and in one specimen (MNHN-IM-2009-17000, Fig. 4D) the cusp is obtuse.
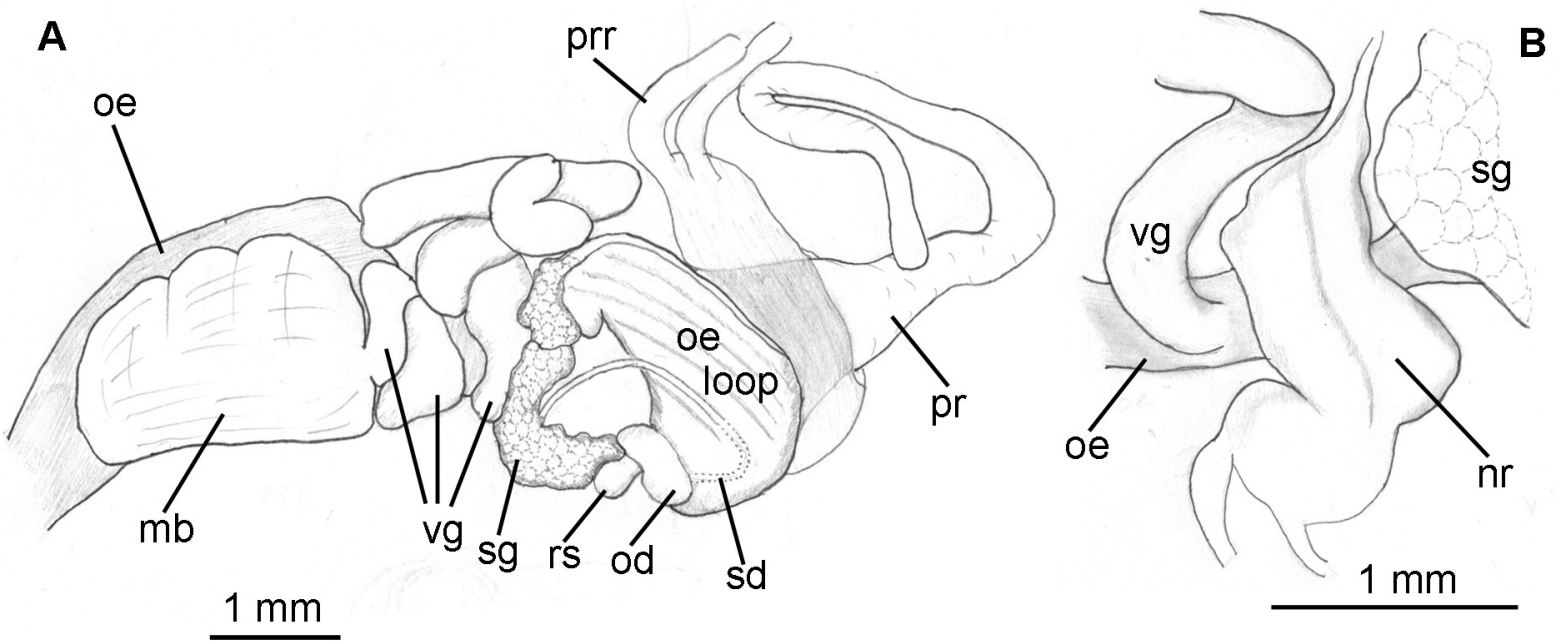

Fig. 5. Anterior foregut of Sibogasyrinx cf. pyramidalis (Schepman, 1913) 2, MNHN-IM-2009-16972. A. Right latero-dorsal view. B. Dorsal view of the nerve ring and opening of the venom gland. Abbreviations: $\mathrm{mb}=$ muscular bulb of the venom gland; $\mathrm{nr}=$ circumoesophageal nerve ring; od = odontophore; oe = oesophagus; $\mathrm{pr}=$ proboscis; prr = proboscis retractors; $\mathrm{rs}=$ radular sac; $\mathrm{sd}=$ salivary duct; sg = salivary gland; $\mathrm{vg}=$ venom gland. 


\section{Remarks}

Despite the similarities in shell and radular morphology, Sibogasyrinx cf. pyramidalis 1 and Sibogasyrinx cf. pyramidalis 2 are clearly distinct from a molecular perspective. One morphological character of the foregut that separates the two species is the presence of an accessory salivary gland in the former.

\section{Distribution}

The confirmed distribution is Papua New Guinea, at 585-827 m.

Sibogasyrinx archibenthalis (Powell, 1969)

Fig. 3R-T

Leucosyrinx (Sibogasyrinx) archibenthalis Powell, 1969: 344, pl. 264 figs 6-7.

\section{Material examined}

\section{Holotype}

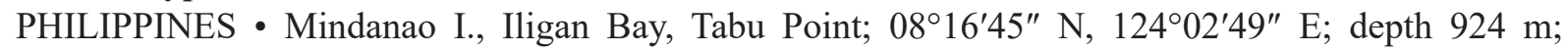
R/V Albatross, stn 5513; USNM 238773.

\section{Description}

Measurements (holotype). SL $41.8 \mathrm{~mm}$.

SHELL. Fusiform, narrow, with high, very narrow, flat-sided spire and relatively short, almost straight, un-notched siphonal canal. Protoconch small, globose, of 1.5 smooth whorls. Teleoconch of 12 whorls. Spire whorl profile quite straight and descending steeply to a narrowly rounded, flange-like, peripheral carina, abutting lower suture. Last whorl distinctly angled by peripheral carina, and base rapidly contracting toward moderately long anterior canal. Axial sculpture of rounded peripheral nodules, about 13 per whorl, but these become obsolete on last two whorls; subsutural nodules or folds lacking. Spiral sculpture of dense well defined and regular spiral cords, 11-12 on subsutural ramp. Anal sinus moderately deep, subsutural, broadly arcuate, confluent with large forward extension of outer lip. Colour opaque white, covered by a thin pale buff periostracum.

\section{Remarks}

The species is known only from the holotype. In shell shape it is most similar to $S$. pyramidalis. The differences are most obvious when comparing specimens of the same size (e.g., Fig.3 D-F and 3R); the last whorl is lower and the canal is proportionally much shorter in S. archibenthalis, while the spiral cords on the subsutural ramp are more pronounced and are of the same strength as on the remaining part of the last whorl. The last whorl is more angular in $S$. archibenthalis and the shell has a higher number of teleoconch whorls; in the holotype of $S$. archibenthalis the number of teleoconch whorls is 12 (SL $43 \mathrm{~mm}$ ), compared with 9.5 (SL $46.8 \mathrm{~mm}$ ) in samples of $S$. cf. pyramidalis 1 from the Philippines of similar shell size. Therefore, at present we consider $S$. archibenthalis to be a valid species.

Sibogasyrinx subula sp. nov. (= PSH 3)

urn:1sid:zoobank.org:act:6A992BBF-7C62-4F15-BFCC-AD9F347ED379

Figs 4E-F, 6

Sibogasyrinx sp. - Bouchet et al. 2011: figs 11b, 12b-c. 


\section{Diagnosis}

Shell large, reaching $57 \mathrm{~mm}$ in length, narrowly fusiform, with concave, nearly smooth subsutural ramp with darker subsutural band on posterior half of last whorl and strong nodules on shoulder. Spiral sculpture of distinct, closely spaced cords below subsutural ramp. Radula with central tooth and duplex marginal teeth.

\section{Etymology}

Latin 'subula' (noun in apposition), meaning 'awl', with reference to the general appearance of the spire.

\section{Material examined}

Holotype

SOLOMON ISLANDS • SE of Sta Isabel I.; $08^{\circ} 17^{\prime} \mathrm{S}, 160^{\circ} 00^{\prime} \mathrm{E}$; depth 482-604 m; SALOMON 2, stn CP2187; MNHN-IM-2007-42530.

Other material (all sequenced)

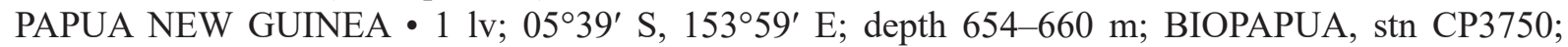
MNHN-IM-2009-17048 • 1 lv; New Ireland; 02¹3' S, 150²1' E; depth 564-743 m; KAVIENG 2014, stn CP4448; MNHN-IM-2013-58409.

SOLOMON ISLANDS • 2 lv; SE of Sta Isabel I.; $08^{\circ} 17^{\prime} \mathrm{S}, 160^{\circ} 00^{\prime} \mathrm{E}$; depth 464-523 m; SALOMON 2, stn CP2184; MNHN-IM-2009-13567, MNHN-IM-2009-13568 • 1 lv; SW of Sta Isabel I.; $08^{\circ} 25^{\prime} \mathrm{S}, 1^{\circ} 9^{\circ} 27^{\prime} \mathrm{E}$; depth 440-521 m; SALOMON 2, stn CP2194; MNHN-IM-2007-42533 • 1 lv; $08^{\circ} 41^{\prime}$ S, $157^{\circ} 38^{\prime}$ E; depth 814-980 m; SALOMON 2, stn CP2276; MNHN-IM-2007-42517.

VANUATU • 4 lv; $15^{\circ} 00^{\prime} \mathrm{S}, 166^{\circ} 55^{\prime} \mathrm{E}$; depth 630-705 m; BOA1, stn CP2432; MNHN-IM-2007-17701 to IM-2007-17704.

\section{Description}

Measurements (holotype). SL $55 \mathrm{~mm}$, AL (with canal) $31 \mathrm{~mm}$, AL (without canal) $17.5 \mathrm{~mm}$, SW $15.6 \mathrm{~mm}$.

SHELL (holotype). Moderately thick, strong except for fragile outer lip of aperture, fusiform, with high spire and long, narrow, straight siphonal canal. Protoconch small, globose, of about 1.5 strongly convex, microshagreened whorls. Protoconch/teleoconch transition marked by arcuate axial rib and appearance of definitive sculpture. Protoconch diameter $1.0 \mathrm{~mm}$, height $0.79 \mathrm{~mm}$. Teleoconch whorls angular at shoulder. Teleoconch comprising just under 10 whorls in total. Suture shallowly impressed, subsutural ramp broad, strongly concave. Subsutural region with a row of distinct sigmoidal nodules that correspond in shape to upper parts of thickened growth lines, about 20 on first whorl, 17-19 on second-fourth whorls, 32 on penultimate and 30 on last whorl. Subsutural ramp smooth except for subsutural row of nodules, few thickened growth lines and 3-4 very weak spiral threads on last and penultimate whorls. Shoulder with pronounced thickened and rounded nodules, weakly opisthocline on upper whorls, but more strongly inclined and confluent with growth lines on last whorl; 17 on penultimate and antepenultimate whorls and 19 on last whorl. Spiral sculpture of 4-5 moderately pronounced, narrow cords on shoulder, seen both on nodules and in their intervals, and rather distinct, weakly rounded cords below shoulder, some flattened. Single cord appears on 3rd whorl, two cords on other whorls, including penultimate one. On last whorl cords occupy entire shell below shoulder, varying in width, their intervals 1-2 times width of cords, in total 48 cords on last whorl, of which 28 on canal. Shell base gradually narrowing towards long, narrow, nearly straight siphonal canal. Aperture narrow, constricted posteriorly, with very narrow and thin parietal callus, outer lip partially broken, with rounded angle at shoulder, weakly convex below shoulder and weakly concave at transition to canal. Anal sinus moderately deep, subsutural, broadly 
arcuate, confluent with large forward extension of outer lip. Shell off-white, with very light yellowish subsutural band and darker subsutural band on posterior half of last whorl, protoconch light tan.

Anatomy ( $\mathrm{n}=1$, MNHN-IM-2009-13568). Head with long cylindrical tentacles, rounded on tips with closely spaced bases, eyes absent. Specimen male, with long penis with obliquely truncated tip. Seminal

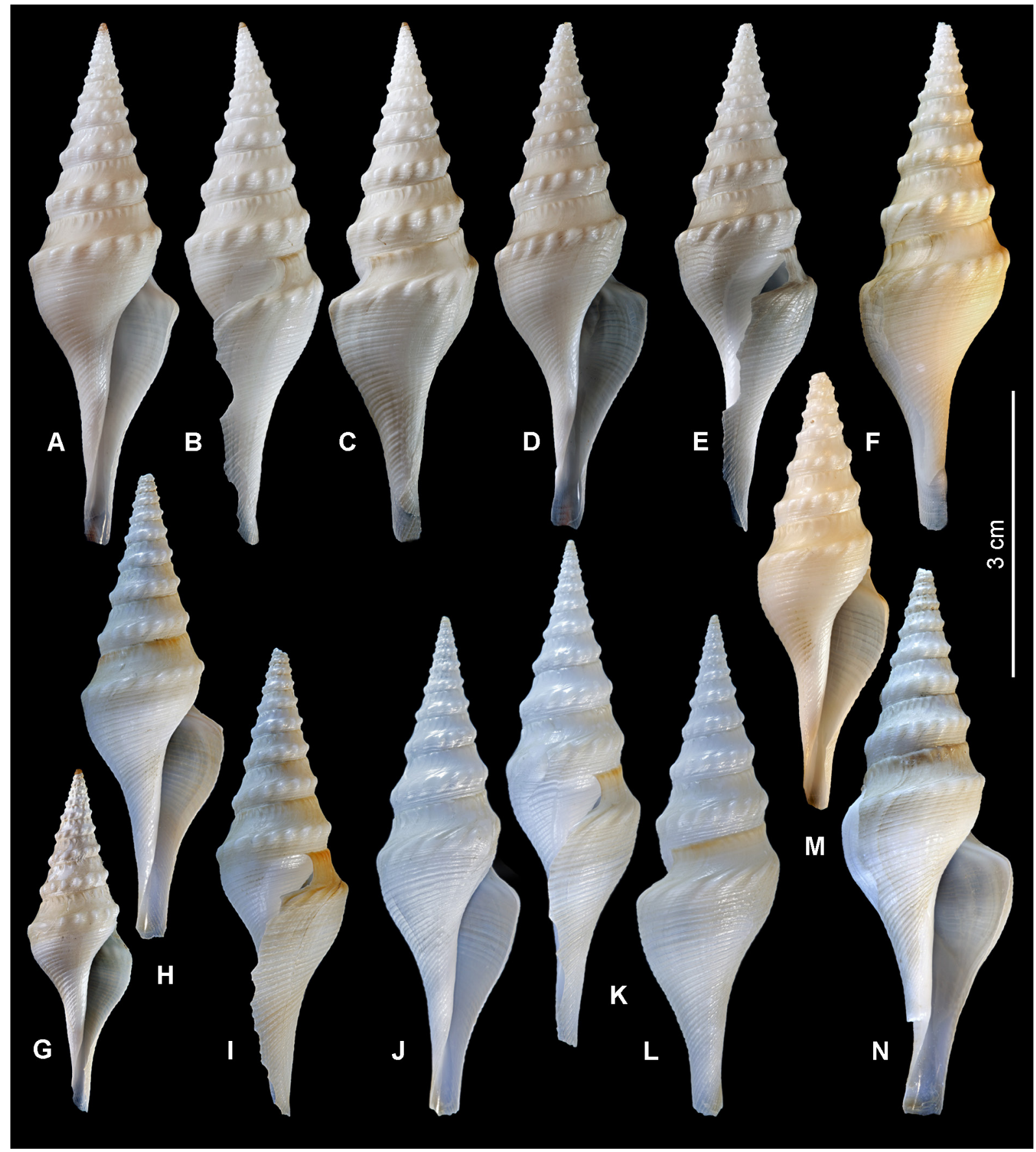

Fig. 6. Sibogasyrinx subula sp. nov. A-C. Solomon Islands, holotype, MNHN-IM-2007-42530, SL 55 mm. D-F. Solomon Islands, MNHN-IM-2007-42533, SL 53.6 mm. G. Papua New Guinea, MNHNIM-2013-58409, SL 36.3 mm. H-I. Solomon Islands, MNHN-IM-2009-13568, SL 49.4 mm (radula seen on Fig. 4F). J-L. Vanuatu, MNHN-IM-2007-17704, SL 53 mm. M. Vanuatu, MNHN-IM-2007-17701, SL $46.0 \mathrm{~mm}$. N. Solomon Islands, MNHN-IM-2009-13567, SL $57.4 \mathrm{~mm}$. All shells to same scale. 
papilla occupies entire tip and is surrounded by circular fold. Proboscis conical, with broad base, but very narrow along most of its length. Proboscis retractors large, arranged in two bundles attached to proboscis base. Buccal mass very large and broad, nearly as long as proboscis, oesophagus forming short loop before nerve ring. Venom gland thick, medium-long and convoluted, opening dorsally into oesophagus just posterior to nerve ring. Muscular bulb very large.

Radula ( $\mathrm{n}=3$; MNHN-IM-2007-17701, MNHN-IM-2007-17703, MNHN-IM-2009-13568). All specimens with similar radular morphology, radula comprising 38-40 rows of teeth, 11-17 nascent, short, length ca $1.8 \mathrm{~mm}$ ( $11 \%$ of AL without canal). Radula width up to $310 \mu \mathrm{m}$ (1.9\% of AL without canal). Central tooth with broad, subrectangular basal plate, anteriorly overlapped by preceding tooth, borders distinct, with narrow, sharply pointed cusp. Marginal teeth with strongly thickened posterior edges, folded longitudinally (Fig. 4E-F), in all details similar to those of Sibogasyrinx cf. pyramidalis 1.

\section{Remarks}

Largest specimen attains an SL of $57.4 \mathrm{~mm}$.

The other specimens are rather similar to the holotype in shell shape and sculpture. The entire subsutural ramp may be pale yellowish on the last whorl, but the subsutural zone of the posterior part of last whorl in larger specimens is always more darkly coloured than the rest of the shell. The subsutural ramp may be completely smooth or with indistinct spiral threads, the shoulder angulation on the last whorl is sometimes less distinct than in the holotype, as may be the cords below the shoulder on the penultimate whorl (up to 4).

In shell outline, the new species resembles its congener Sibogasyrinx filosa, but differs in having much less distinct spiral sculpture on the subsutural ramp, as well as in its larger size (maximal SL $57.4 \mathrm{~mm}$ in S. subula sp. nov. and $52 \mathrm{~mm}$ in S. filosa) and radular morphology. The shell shape of the new species also strongly resembles that of some species of Leucosyrinx, particularly L. verrillii (Dall, 1881) (Fig. 13A-C) and to a lesser extent the smaller specimens of Leucosyrinx sp. B and Leucosyrinx sp. G (Fig. 13D and 13I, respectively). All these species of Leucosyrinx, however, have a different radular morphology, shorter siphonal canal and, according to the molecular tree (Fig. 1) and other published Conoidea phylogenies (Puillandre et al. 2011; Abdelkrim et al. 2018), belong to a different family.

\section{Distribution}

This species is known from the Solomon Islands, Papua New Guinea and Vanuatu, and has a relatively broad bathymetric range, from 440 to $814 \mathrm{~m}$.

Sibogasyrinx sangeri Kantor, Fedosov \& Puillandre, 2018 (= PSH 7)

Figs $7,8 \mathrm{~A}-\mathrm{B}$

Sibogasyrinx sangeri Kantor, Fedosov \& Puillandre, 2018: 58, figs 5e-n, 6c-d.

\section{Material examined}

Holotype

PAPUA NEW GUINEA • $07^{\circ} 52^{\prime} \mathrm{S}, 148^{\circ} 03^{\prime} \mathrm{E}$; depth 575-655 m; BIOPAPUA, stn CP3729; MNHNIM-2009-17022 (sequenced).

Other material (all sequenced)

PAPUA NEW GUINEA - 2 lv; 04 $04^{\prime}$ S, 151 ${ }^{\circ} 56^{\prime} \mathrm{E}$; depth 585-601 m; BIOPAPUA, stn CP3671; MNHN-IM-2009-16989, MNHN-IM-2013-52052 - 1 lv; 0424' S, 151 ${ }^{\circ} 50^{\prime}$ E; depth 788-805 m; 
BIOPAPUA, stn CP3674; MNHN-IM-2009-16995 • 1 1v; off Woodlark Is.; 0908' S, $152^{\circ} 19^{\prime}$ E; depth 448-470 m; BIOPAPUA, stn CP3742; MNHN-IM-2009-17057 • 1 lv; 0539' S, 153⒌ $59^{\prime}$ E; depth 654660 m; BIOPAPUA, stn CP3750; MNHN-IM-2009-17021 • 1 lv; N of Long I.; 05²10' S, $147^{\circ} 03^{\prime}$ E; depth 724 m; PAPUA NIUGINI, stn CP3982; MNHN-IM-2013-19752 • 1 lv; Dampier Strait, E of Umboi I.; 053' S, $148^{\circ} 13^{\prime}$ E; depth 630-870 m; PAPUA NIUGINI, stn CP4014; MNHN-IM-2013-19961.

PHILIPPINES • $1 \mathrm{lv} ; 15^{\circ} 45^{\prime} \mathrm{N}, 121^{\circ} 45^{\prime} \mathrm{E}$; depth $562 \mathrm{~m}$; AURORA 2007, stn CP2663; MNHNIM-2009-13434.

SOLOMON ISLANDS • 1 lv; Sta Isabel I.; 08 $47^{\prime} \mathrm{S}, 159^{\circ} 40^{\prime} \mathrm{E}$; depth 645-840 m; SALOMON 2,

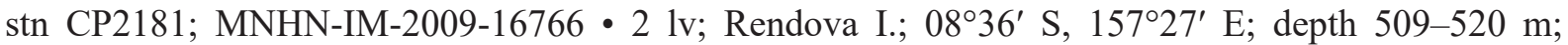
SALOMON 2, stn CP2288; MNHN-IM-2007-42523, MNHN-IM-2009-16779.

\section{Description}

MeAsurements. Holotype: SL $54.1 \mathrm{~mm}$, AL (with canal) $31.3 \mathrm{~mm}$, AL (without canal) $16.4 \mathrm{~mm}$, SW $14.1 \mathrm{~mm}$. Largest available specimen attains SL 55.8 mm (MNHN-IM-2009-16779; Fig. 7D-E).

SHELL. Thin, fragile, variable in shape, from narrowly fusiform to moderately broad (SW/SL ratio from 0.22 to 0.27 ), with rather high spire and long, narrow, straight siphonal canal. Protoconch small, globose, of 1.75 strongly convex, microshagreened whorls. Protoconch/teleoconch transition indistinct. Protoconch diameter about $1.1 \mathrm{~mm}$, height $1.2 \mathrm{~mm}$. Early teleoconch whorls angular, usually in lower part just above suture, but sometimes at mid-whorl; last whorl strongly to very weakly angled or evenly rounded, even in specimens of the same size. Teleoconch comprising up to 10 whorls. Suture shallow, subsutural ramp with a row of distinct, closely spaced nodules, 10 on first whorl, 14 on second whorl, becoming more broadly spaced and less discernible on later whorls, sometimes obsolete on last whorl of largest specimens. Subsutural zone very weakly concave, nearly straight on penultimate and last whorls, smooth except for a few irregularly spaced and indistinct spiral threads (sometimes oblique), or several rather pronounced flattened spiral cords (Fig. 7J; MNHN-IM-2009-13434). Lower part of whorls with a row of larger, more pronounced nodules, just above suture in upper whorls or sometimes nearer midwhorl. In some specimens nodules absent on last whorl. Last whorl may bear low carina at periphery (in specimens with nodules absent), giving it very weakly angled outline. Below periphery $2-3$ distinct spiral cords on penultimate whorl and about 30 cords below carina on last whorl and 20 on canal. Shell base gradually narrowing towards long, nearly straight siphonal canal. Aperture narrow, constricted posteriorly with broad, very thin parietal callus, outer lip partially broken, convex and weakly angled in upper part and slightly convex below shoulder, and shallowly concave at transition to canal. Anal sinus moderately deep, subsutural, broadly arcuate, growth lines confluent with large forward extension of outer lip. Growth lines thin but distinct. Shell uniformly off-white, protoconch light tan.

AnAtomy ( $\mathrm{n}=1$, MNHN-IM-2009-16995). Proboscis of moderate length in contracted stage, buccal mass situated outside proboscis. Oesophagus very broad, forming short loop before passing through nerve ring. Venom gland opening into oesophagus ventrally and immediately posterior to nerve ring.

RADULA ( $\mathrm{n}=1$, MNHN-IM-2009-16995) (Fig. 8A-B). Relatively short, comprising ca 40 rows of teeth, with long nascent part (15-16 rows). Radula length $2.2 \mathrm{~mm}$ (16\% of AL without canal), width up to $365 \mu \mathrm{m}$ (2.7\% of AL without canal). Central tooth with subrectangular basal plate, very shallowly arcuate anteriorly, with distinct borders and weak cusp. Marginal teeth flat when formed, becoming trough-shaped during maturation, folded longitudinally when fully formed. On developing part of radula, folding of teeth occurs abruptly, within one subsequent row (on Fig. 8B white arrow indicates last still unfolded tooth, while black arrow with white outline indicate the first folded tooth). Folding 
evident at $17^{\text {th }}$ row in radula studied. Resulting folded tooth moderately broad, with sharp pointed tip, formed by overlapping of both thickened margins (on Fig. 8A these overlapping parts are marked by hollow white arrows).

\section{Distribution}

This species is known from the Solomon Islands, Papua New Guinea and the Philippines, over a relatively broad bathymetric range, from 448 to $788 \mathrm{~m}$.

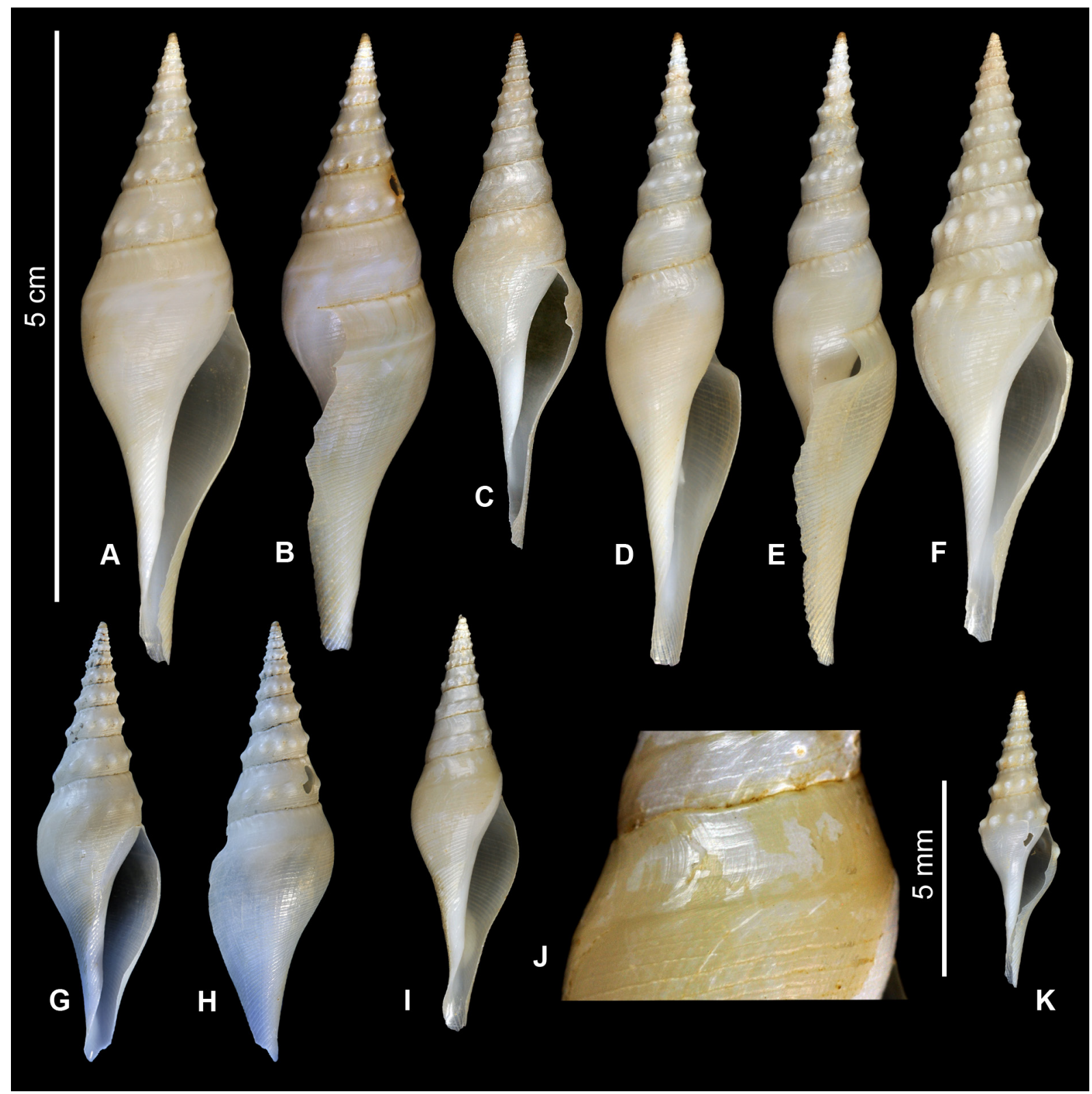

Fig. 7. Sibogasyrinx sangeri Kantor, Fedosov \& Puillandre, 2018. A-B. Holotype, Papua New Guinea, MNHN-IM-2009-17022, SL 54.1 mm. C. Papua New Guinea, MNHN-IM-2009-16995, SL 47.7 mm (radula seen on Fig. 8A-B). D-E. Solomon Islands, MNHN-IM-2009-16779, SL 55.8 mm. F. Papua New Guinea, MNHN-IM-2009-17021, SL 53.7 mm. G-H. Papua New Guinea, MNHN-IM-2009-17057, SL 38.8 mm. I-J. Philippines, MNHN-IM-2009-13434, SL 36.9 mm. K. Solomon Islands, MNHNIM-2009-16766, SL $26.3 \mathrm{~mm}$. All shells to the same scale. 
Sibogasyrinx filosa Ardovini, 2021 (= PSH 6)

Figs $8 \mathrm{C}, 9 \mathrm{~A}-\mathrm{H}$

Sibogasyrinx filosus Ardovini, 2021: 5-6, textfigs (erroneous gender agreement of specific epithet).

\section{Material examined}

Holotype

PAPUA NEW GUINEA • lv; NE of Bougainville I.; 04³0' S, 157²0' E; depth 1100-1200 m; MNHN-IM-2000-37629 (originally R. Ardovini collection).

\section{Paratype}

PAPUA NEW GUINEA • 1 lv; same collection data as for holotype; R. Ardovini collection.

Other material (all sequenced)

PAPUA NEW GUINEA • 1 lv; New Ireland; 02³3' S, 15045’ E; depth 150-170 m; KAVIENG 2014, stn DW4500; MNHN-IM-2013-59044.

SOLOMON ISLANDS • 1 lv; off Choiseul I., Papua New Guinea Exclusive Economic Zone; $06^{\circ} 37^{\prime}$ S, $156^{\circ} 13^{\prime}$ E, depth 508-522 m; SALOMON 2, stn CP2227; MNHN-IM-2007-42498 • 1 lv; Guadalcanal I.; $09^{\circ} 19^{\prime} \mathrm{S}, 160^{\circ} 06^{\prime} \mathrm{E}$; depth 416-425 m; SALOMONBOA 3, stn CP2767; MNHN-IM-2009-16831.

\section{Description}

MEASUREMENTS. Largest available specimen (MNHN-IM-2007-42498): SL 49.9 mm, AL (with canal) $28 \mathrm{~mm}$, AL (without canal) $16.7 \mathrm{~mm}, \mathrm{SW} 13.5 \mathrm{~mm}$. Holotype has SL $52 \mathrm{~mm}$.

SHELL. Moderately thick, strong except for fragile and often partially broken outer aperture lip, narrowly fusiform, with high spire and long, narrow, straight siphonal canal. Protoconch small, globose, of just over 1.5 strongly convex, microshagreened whorls (MNHN-IM-2009-16831). Protoconch/teleoconch transition indistinct, marked by appearance of shoulder carina. Protoconch diameter $0.89 \mathrm{~mm}$, height $0.72 \mathrm{~mm}$. Spire whorls strongly angled at shoulder, last whorl with more rounded shoulder. Total teleoconch whorls just under 9 in largest specimen. Suture shallowly impressed on last whorl and rather deep on spire ones, subsutural ramp moderately broad, strongly concave. Subsutural region with a row of distinct narrow axial ribs, confluent with growth lines and forming small nodules at intersections with spiral cords, absent on most of first teleoconch whorl, about 20 on second-third whorls, about 35 on penultimate and 45 on last whorl. Subsutural ramp with spiral cords, first visible on second whorl and distinct on fourth whorl. Last, penultimate and antepenultimate whorls with 4-5 distinct cords on subsutural ramp, their intervals equal to width of cords, followed below shoulder by 5-7 more narrow, closely spaced cords. Shoulder with row of pronounced rounded nodules, more distinct on upper teleoconch whorls and absent on last whorl, 15-17 on penultimate and antepenultimate whorls. Spiral sculpture in addition to cords on subsutural ramp of distinct narrow cords, covering entire shell surface, including shoulder nodules. On last whorl about 45 cords below shoulder, 25 of which on canal. Cords weakly rounded or flat on top, their intervals mostly narrower than cords themselves, rarely equal to or even slightly wider than cords. Shell base gradually narrowing towards long, narrow, almost straight siphonal canal. Aperture narrow, constricted posteriorly, with very narrow and thin parietal callus, outer lip with rounded angle at shoulder, weakly convex below shoulder, weakly concave at transition to canal. Anal sinus moderately deep, subsutural, broadly arcuate, confluent with large forward extension of outer lip. Shell light orange with lighter middle part of last whorl, in sequenced specimens off-white, with very light yellowish subsutural ramp and irregular darker blotches on subsutural ramp. Protoconch light tan. 

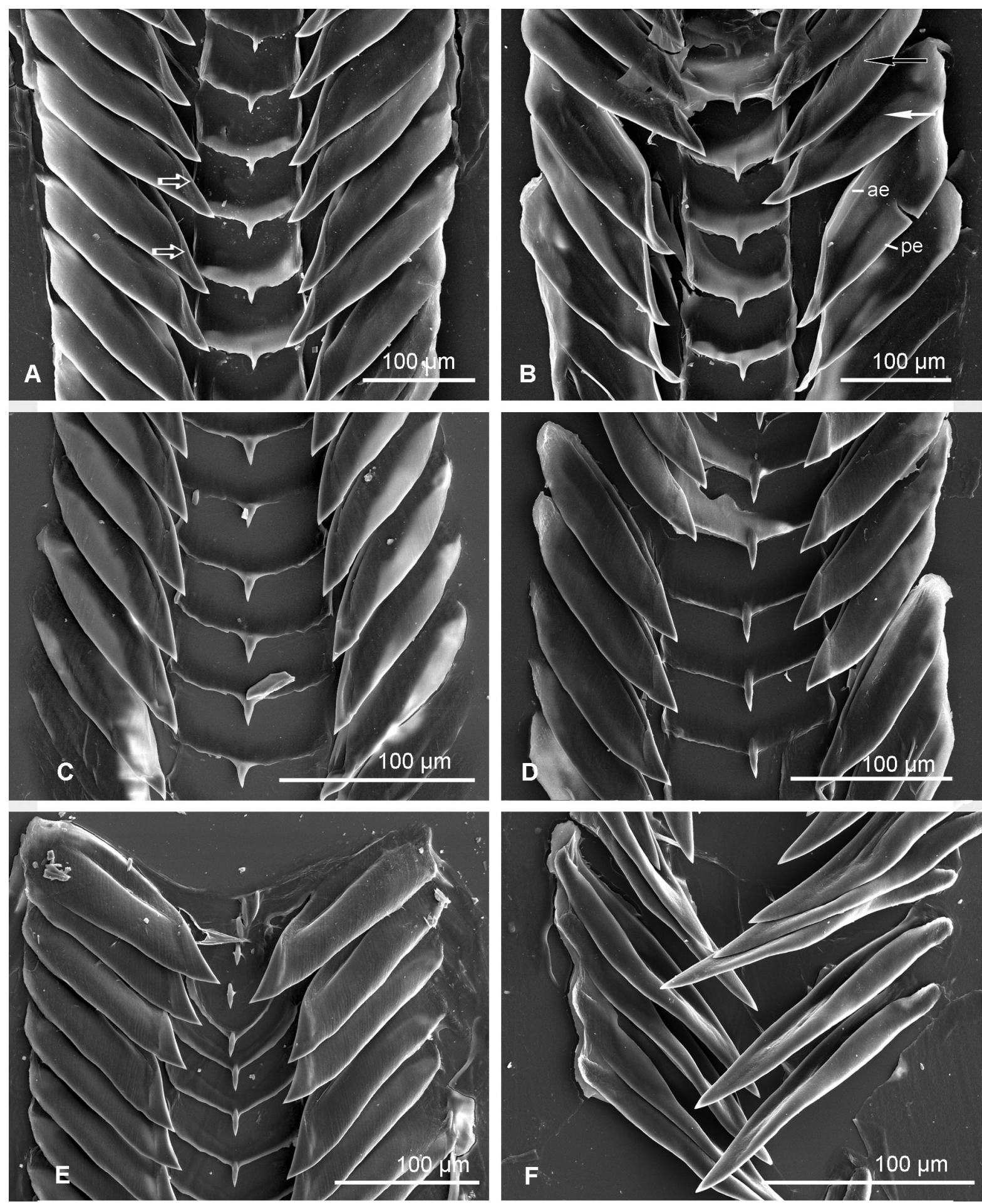

Fig. 8. Radulae of species of Sibogasyrinx Powell, 1969. A-B. Sibogasyrinx sangeri Kantor, Fedosov \& Puillandre, 2018, MNHN-IM-2009-16995 (shell seen on Fig. 7C). A. Part of radula with fully formed marginal teeth; white hollow arrow indicates overlapping edges of the tooth at its tip. B. Part of radula showing transition between unfolded (white arrow) and completely longitudinally folded (black arrow) marginal teeth $(\mathrm{ae}=$ anterior tooth edge; $\mathrm{pe}=$ posterior tooth edge). C. Sibogasyrinx filosa Ardovini, 2021, Solomon Islands, MNHN-IM-2009-16831 (shell seen Fig. 9E-F). D. Sibogasyrinx lolae sp. nov., MNHN-IM-2009-29311. E. Sibogasyrinx maximei sp. nov., holotype, MNHN-IM-2013-45883, anterior end of radula. F. Sibogasyrinx pagodiformis sp. nov., MNHN-IM-2009-11327. 
ANATOMy ( $\mathrm{n}=1$; MNHN-IM-2009-16831). Head with moderately long, conical tentacles, rounded on tips and with closely spaced bases, large eyes situated on small lobes at tentacle base. Proboscis conical, moderately long, with broad base, rapidly narrowing towards tip. Proboscis retractors not defined, entire posterior part of very thin proboscis sheath base weakly muscular. Buccal mass very large and broad, posterior to proboscis base, constituting about half of proboscis length, oesophagus forming a very short loop before nerve ring. Radular sac with small odontophore, opening dorso-laterally at right side of buccal mass. Venom gland thick, moderately long and convoluted, opening into oesophagus within nerve ring. Muscular bulb moderately large, elongated and folded in posterior part. Salivary glands fused, relatively large, of irregular shape, acinous. Small ovate accessory salivary gland situated dorsally at nerve ring.

RAdULA ( $\mathrm{n}=1$; MNHN-IM-2009-16831) (Fig. 8C). Relatively short, consisting of 41 rows of teeth, 15 nascent. Radula length $1.55 \mathrm{~mm}$ ( $12 \%$ of AL without canal), width up to $225 \mu \mathrm{m}$ ( $1.8 \%$ of AL without canal). Central tooth with subrectangular basal plate, having distinct borders and moderately long cusp. Anterior margin overlapped by preceding row, posterior margin evenly and weakly rounded. Marginal teeth flat when formed, becoming trough-shaped with weakly thickened edges during maturation, folded longitudinally when fully formed, with both margins overlapping at tooth tip. Resulting folded tooth moderately broad, with sharp pointed tip, anterior edge with a narrow slit between folded tooth margins.

\title{
Remarks
}

Our specimens are very similar to the holotype and paratype (except lighter shells) and were collected close to the type locality. Our specimens were collected at much shallower depths $(150-508 \mathrm{~m})$ as compared to the holotype and paratype $(1100 \mathrm{~m})$. Nevertheless, the strong similarity of the shell shape and sculpture, especially obvious when comparing the holotype with sequenced specimen of the same size (Fig. 9A-B and C-D) suggests the conspecifity of our and the type specimens. Ardovini (2021) himself considered the specimen MNHN-IM-2007-42498 as belonging to his newly described species based on the photograph on the MNHN website. Smaller specimens (SL 34.4 and $29.9 \mathrm{~mm}$ ) retain smooth, flaking, yellowish periostracum, better preserved in interspaces between cords.

This species is most similar to Sibogasyrinx subula sp. nov., but differs in having more strongly developed spiral cords on the subsutural ramp, a relatively narrower ramp resulting in a higher shoulder position on the spire whorls, a different radula and the presence of eyes. In shell outline the new species resembles some species of Leucosyrinx, particularly Leucosyrinx sp. A (Fig. 13H), but the shell is broader with more numerous nodules on the shoulder. Compared to Leucosyrinx sp. F (Fig. 13K), the shell of S. filosa is larger, broader and has a coarser sculpture.

\section{Distribution}

This species is found off the Solomon Islands Archipelago and New Ireland, at a broad depth range of $150-1100 \mathrm{~m}$.

\author{
Sibogasyrinx lolae sp. nov. (= PSH 8) \\ urn:1sid:zoobank.org:act:73404289-ED57-4ABD-A0D0-05939F095C40
}

Figs 8D, 9I-Q

\section{Diagnosis}

Shell medium-sized, reaching $43 \mathrm{~mm}$ in length, fusiform, with weakly concave, nearly smooth subsutural ramp and nodules on shoulder of upper teleoconch whorls, absent on later whorls of large specimens. Spiral sculpture weak, of closely spaced cords covering entire shell except subsutural ramp in some specimens. Radula with central tooth and longitudinally folded marginal teeth with weakly thickened edges. 


\section{Etymology}

The species is named after Lola, the daughter of the second author.

\section{Material examined}

\section{Holotype}

SOLOMON ISLANDS • W of San Cristobal I.; $10^{\circ} 26^{\prime} \mathrm{S}, 161^{\circ} 20^{\prime} \mathrm{E}$; depth 506-567 m; SALOMONBOA 3, stn CP2839; MNHN-IM-2007-42537.

Other material (all sequenced)

NEW CALEDONIA • 1 lv; Bank de L'Orne/Walpole; 22 22' S, 168 57' E; depth 460-708 m; EXBODI,

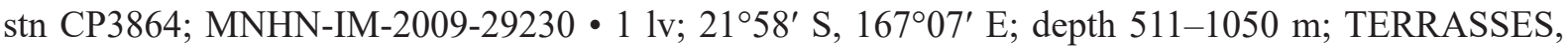
stn CP3098; MNHN-IM-2009-29311 • 1 lv; Fairway Ridge; 2139' S, 162 $42^{\prime}$ E; depth 787 m; KANADEEP, stn CP4923; MNHN-IM-2013-48156.

\section{Description}

MEASUREMENTs (holotype). SL $37.3 \mathrm{~mm}$, AL (with canal) $22.9 \mathrm{~mm}$, AL (without canal) $14.5 \mathrm{~mm}$, SW $11.3 \mathrm{~mm}$.

SHELL (holotype). Moderately thick, glossy, strong except for very fragile and partially broken outer aperture lip, narrowly fusiform, with high spire and long, narrow, straight siphonal canal. Protoconch small, globose, corroded, of about 1.5 whorls. Protoconch preserved in other juvenile specimen (MNHN-IM-2013-48156), comprising just over 1.5 strongly convex, microshagreened whorls. Protoconch/teleoconch transition indistinct, marked by appearance of axial ribs. Protoconch diameter $1.0 \mathrm{~mm}$, height $0.74 \mathrm{~mm}$. Spire whorls angled at shoulder, last whorl with less angular shoulder. Total teleoconch whorls just under 8. Suture shallowly impressed on last whorl and rather deep on spire whorls, subsutural ramp moderately broad, weakly concave on upper teleoconch whorls and nearly flat on penultimate and last whorls. Subsutural ramp with distinct prosocline axial wrinkles, extending from suture to upper $2 / 3$ of ramp, 22-23 on first and second whorls, 24 on penultimate and 31 on last whorl, and without spiral sculpture on upper four whorls and later with indistinct spiral cords, three on last whorl. Shoulder of teleoconch whorls (except last one) with a row of distinct, opisthoclinely elongated nodules, intersected by weak spiral cords. Seventeen nodules on first teleoconch whorl, 18 on antepenultimate and penultimate whorls. Weak spiral cords on and below shoulder, starting from $3^{\text {rd }}$ teleoconch whorls, about twice as wide below shoulder. Penultimate whorl with four cords on shoulder and four below shoulder. Shoulder smooth on last whorl, but with about 55 cords below shoulder, of which 25 on canal. Cords weak, slightly wavy and closely spaced, their intervals about half the width of cords. Shell base gradually narrowing towards long, narrow, nearly straight siphonal canal. Aperture narrow, constricted posteriorly, with narrow, very thin parietal callus, outer lip badly broken, distinctly impressed at shoulder, weakly convex below shoulder and shallowly concave at transition to canal. Anal sinus judging from growth lines shallow, subsutural, broadly arcuate, confluent with forward extension of outer lip. Shell very light yellowish, protoconch very light tan (in holotype) and light brown in MNHN-IM-2013-48156.

Anatomy ( $\mathrm{n}=1$; MNHN-IM-2009-29311). Male. Penis tip obliquely truncated, with long and very narrow papilla, surrounded by circular fold, much larger in diameter than papilla itself. Proboscis conical, moderately long, with broad base, anterior half rapidly narrowing towards tip. Proboscis retractors distinct, arranged in two symmetrical lateral bundles, attached to inner proboscis walls at border of its posterior third. Buccal mass with small radular sac, odontophore situated within proboscis in its broader posterior part; elongate oval, occupying slightly less than half of proboscis length. Single small accessory salivary gland present. Salivary glands separate, acinous, irregular in shape. Venom gland long, moderately thick and convoluted, opening into oesophagus within the nerve ring. 


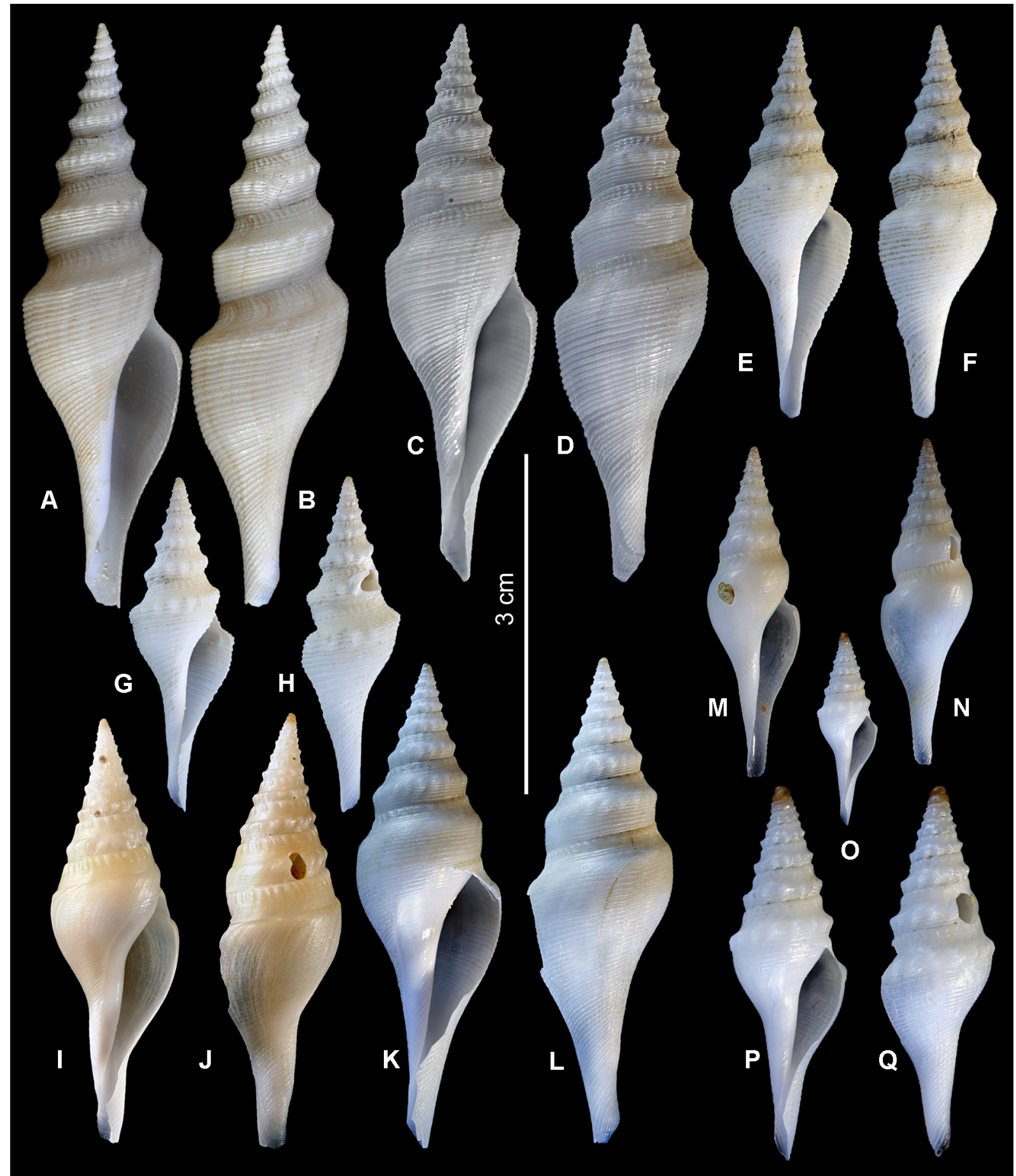

Fig. 9. A-H. Sibogasyrinx filosa Ardovini, 2021. A-B. Holotype, Solomon Islands (MNHNIM-2000-37629), SL $52 \mathrm{~mm}$. C-D. Solomon Islands, MNHN-IM-2007-42498, SL $49.9 \mathrm{~mm}$. E-F. Solomon Islands, MNHN-IM-2009-16831, SL 34.4 mm (radula seen on Fig. 8C). G-H. Papua New Guinea, MNHN-IM-2013-59044, SL 29.9 mm. I-Q. Sibogasyrinx lolae sp. nov. I-J. Solomon Islands, holotype, MNHN-IM-42537, SL 37.3 mm. K-L. New Caledonia, MNHN-IM-2009-29230, SL $43.1 \mathrm{~mm}$. M-N. New Caledonia, MNHN-IM-2009-29311, SL $29.1 \mathrm{~mm}$. O-Q. New Caledonia, MNHN-IM-2013-48156, SL $17.1 \mathrm{~mm}$ (O at the same scale as the other specimens, P-Q enlarged). All shells (except P-Q) to same scale. 
Radula ( $=1$; MNHN-IM-2009-29311) (Fig. 8D). Short, comprising 28 rows of teeth, 13 nascent. Radula length $1.15 \mathrm{~mm}$ (7.9\% of AL without canal), width up to $255 \mu \mathrm{m}$ (1.8\% of AL without canal), tooth length $160 \mu \mathrm{m}(1.10 \%$ of AL without canal). Central tooth with subrectangular basal plate, having distinct borders and long, narrow, sharp cusp. Anterior margin overlapped by preceding row, posterior margin formed by two straight sections meeting at obtuse angle in midline. Marginal teeth flat when formed, becoming trough-shaped with weakly thickened edges during maturation, folded longitudinally when fully formed, with both margins overlapping at tooth tip. Resulting folded tooth moderately broad, with sharp pointed tip, anterior edge with a narrow slit between tooth margins. Tooth folding occurring within $15^{\text {th }}$ row of teeth.

\title{
Remarks
}

The largest specimen attains $43.1 \mathrm{~mm}$.

Other specimens are similar to the holotype in shell shape, although some have much more pronounced spiral sculpture, especially MNHN-IM-2009-29230, which also retains spiral cords on the shoulder of the last whorl.

In shell shape and sculpture the new species is most similar to Sibogasyrinx filosa, some specimens being almost indistinguishable (e.g., holotype of S. filosa and MNHN-IM-2009-29230). Sibogasyrinx lolae sp. nov. can be distinguished from $S$. filosa due to its generally less distinct spiral sculpture and less concave, nearly flat subsutural ramp. Other conchologically similar species are $S$. cf. pyramidalis 1 and 2 , but these differ in their radular morphology. In both these species and $S$. lolae sp. nov., the nodules on the shoulder become less pronounced or disappear on later whorls. Nevertheless, the nodules are still pronounced on the shoulder of the last whorl in specimens of $S$. cf. pyramidalis 1 and 2 of the same size as specimens of $S$. lolae sp. nov. which already lack nodules on the last whorl.

\section{Distribution}

This species is recorded from the Solomon Islands, the Coral Sea and southern New Caledonia, at depths of $460-787 \mathrm{~m}$.

\author{
Sibogasyrinx maximei sp. nov. (= PSH 9) \\ urn:1sid:zoobank.org:act:EEC38F7C-DD00-46B9-9D56-3915EB0B2CD2
}

Figs $8 \mathrm{E}, 10 \mathrm{~A}-\mathrm{C}$

\section{Diagnosis}

Shell medium-sized, reaching $41.6 \mathrm{~mm}$ in length, fusiform, subsutural ramp weakly concave on early teleoconch whorls, flat on later ones. It is nearly smooth (except for axial riblets). Shoulder of teleoconch whorls with nodules, absent on last whorl. Spiral sculpture weak, of indistinct closely spaced cords on and below shoulder. Radula with central tooth and longitudinally folded marginal teeth with weakly thickened edges.

\section{Etymology}

This species is named after Maxime, the son of the second author.

\section{Material examined}

Holotype

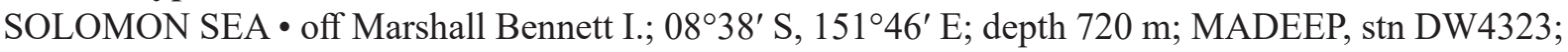
MNHN-IM-2013-45883. 
Description (holotype)

MEASUREMENTs. SL $41.6 \mathrm{~mm}$, AL (with canal) $23.2 \mathrm{~mm}$, AL (without canal) $15.7 \mathrm{~mm}$, SW $12.4 \mathrm{~mm}$.

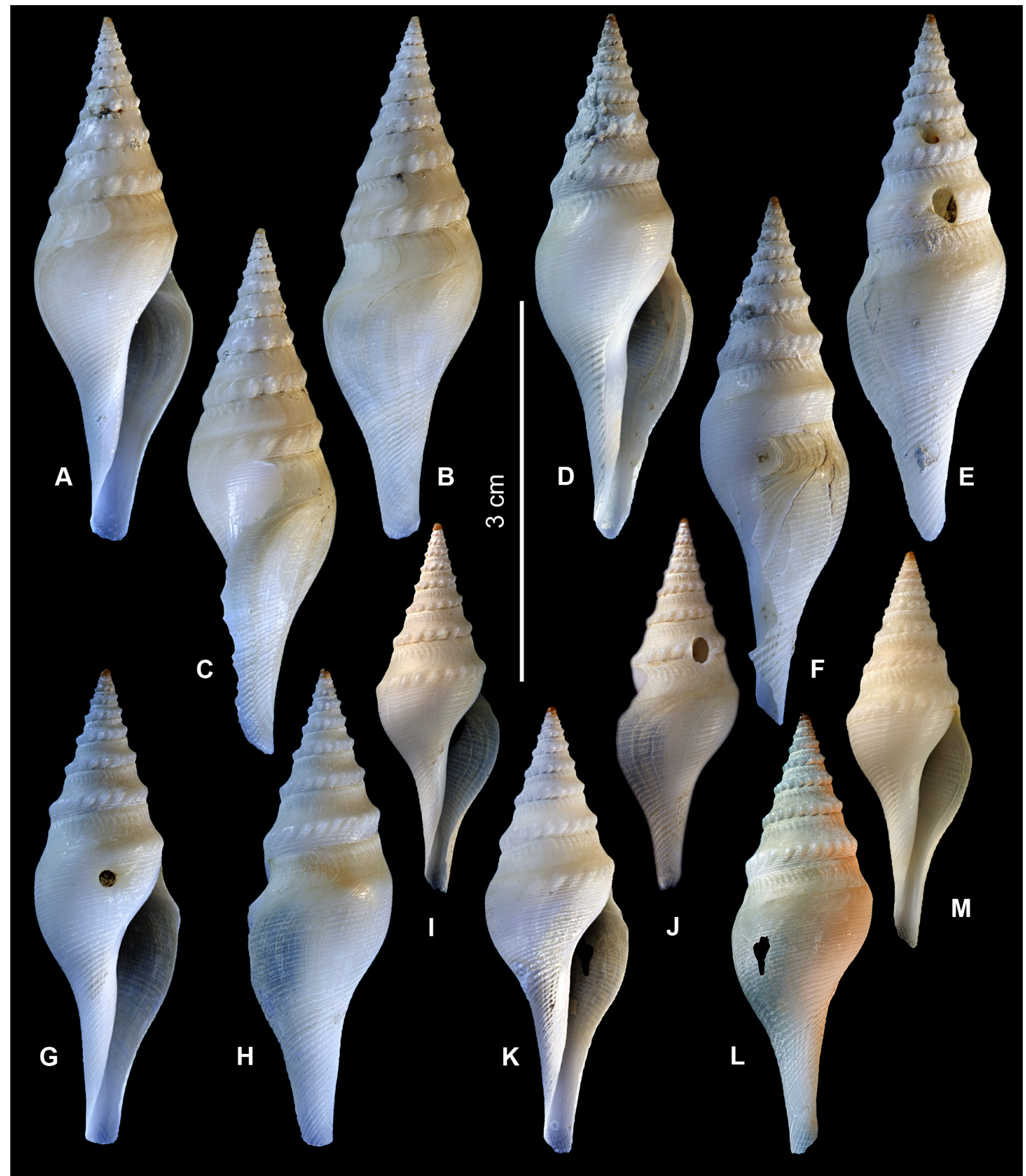

Fig. 10. A-C. Sibogasyrinx maximei sp. nov., Solomon Sea, holotype, MNHN-IM-2013-45883, SL $41.6 \mathrm{~mm}$. D-M. Sibogasyrinx clausura sp. nov. D-F. Solomon Islands, holotype, MNHNIM-2013-48256, SL 41.4 mm. G-H. Coral Sea, Coriolis Bank, MNHN-IM-2013-48167, SL 37.9 mm. I-J. Solomon Islands, MNHN-IM-2009-16763, SL 29.6 mm. K-L. Coral Sea, Coriolis Bank, MNHNIM-2013-48244, SL 35.6 mm. M. Coral Sea, Coriolis Bank, MNHN-IM-2013-48144, SL 31.7 mm. All shells to same scale. 
SHELL. Moderately thick, strong except for fragile and partially broken outer aperture lip, fusiform, with high, conical spire and moderately long, broad, straight siphonal canal. Protoconch small, globose, of about 1.5 strongly convex, microshagreened whorls. Protoconch/teleoconch transition marked by strongly arcuate axial rib, corresponding to shape of growth line. Protoconch diameter $1.0 \mathrm{~mm}$, height $0.83 \mathrm{~mm}$. Spire whorls weakly angled at shoulder, last whorl with hardly discernible shoulder. Total teleoconch whorls 8.5 . Suture shallowly impressed, subsutural ramp broad, weakly concave on first four teleoconch whorls, flat on later whorls. Subsutural ramp with short, distinct, prosocline axial wrinkles, corresponding to upper parts of thickened growth lines, extending from suture to upper $1 / 3$ of ramp, increasing in number from 20 on first whorl to 34 on penultimate and 43 on last whorl. Subsutural ramp with only traces of indistinct spiral striation. Shoulder of teleoconch whorls (except last one) with a row of distinct elongated nodules, these nearly orthocline on upper whorls and weakly opisthocline on penultimate whorl, 14-17 per whorl, reaching lower suture and intersected by spiral cords. Starting from $2^{\text {nd }}$ teleoconch whorl, spiral cords appearing on shoulder, these intersecting nodules and becoming progressively stronger, from two on $2^{\text {nd }}$ whorl to nine on penultimate one. Cords very closely spaced, separated by narrow grooves. On last whorl cords cover entire shell surface below indistinct shoulder, about 50 cords in total, of which 25 on canal. Cords weak, slightly wavy, very closely spaced just below suture and with intervals $0.5-1.0$ times width of cords on shell base and canal. Shell base gradually narrowing towards moderately broad, almost straight siphonal canal. Aperture narrow, constricted posteriorly, with narrow and very thin parietal callus, outer lip partially broken, evenly convex and weakly concave at transition to canal. Anal sinus moderately deep, subsutural, broadly arcuate, confluent with large forward extension of outer lip. Shell very light yellowish, protoconch light tan. Periostracum smooth, tightly adhering.

Radula ( $=1$; MNHN-IM-2013-45883) (Fig. 8E). Medium-long, comprising 40 rows of teeth, 12 nascent. Radula length $1.8 \mathrm{~mm}$ (11.4\% of AL without canal), width up to $290 \mu \mathrm{m}(1.85 \%$ of AL without canal). Central tooth with basal plate, having distinct borders and long, narrow, sharp cusp, anterior margin overlapped by preceding row, posterior margin formed by two straight sections meeting at obtuse angle in midline. Marginal teeth flat when formed, becoming trough-shaped with weakly thickened edges during maturation, folded longitudinally when fully formed, with both margins overlapping at tooth tip. Resulting folded tooth moderately broad with sharply pointed tip, border between both margins present as a narrow slit at anterior edge. Tooth folding occurring within $14^{\text {th }}$ row of teeth (counting from rear).

\section{Remarks}

The species is known from the holotype alone and is very similar to Sibogasyrinx clausura sp. nov. (for comparison see remarks under the following species). In shell outline it is very similar to $S$. cf. pyramidalis 1 and 2, but differs in having fewer nodules on the shoulder; the holotype has 17 nodules on the penultimate whorl, whereas specimens of $S$. cf. pyramidalis 1 and 2 of similar size have up to 26 nodules. There are additional differences in radular morphology.

\section{Distribution}

Known only from the type locality.

Sibogasyrinx clausura sp. nov. (= PSH 10)

urn:1sid:zoobank.org:act:27ED0BF0-C78A-41E1-9064-E3EB0492864A

Figs 10D-M, 11A-B

\section{Diagnosis}

Shell medium-sized, reaching $41.5 \mathrm{~mm}$ in length, fusiform, subsutural ramp concave on upper teleoconch whorls, weakly so on last whorl, nearly smooth (except for the axial riblets), shoulder bearing nodules on 
spire whorls, absent on last whorl. Spiral sculpture of weak, closely spaced cords on and below shoulder. Radula with central tooth and longitudinally folded marginal teeth with weakly thickened edges.

\section{Etymology}

Latin 'clausura' (noun in apposition), meaning 'lockdown', with reference to the sanitary restrictions associated with SARS-COV-2 that prevailed over much of the World when this manuscript was finalized.

\section{Material examined}

\section{Holotype}

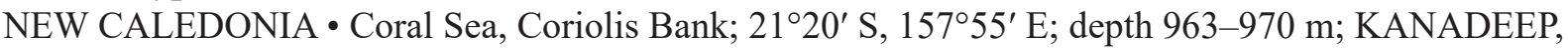
stn CP4964; MNHN-IM-2013-48256.

Other material (all sequenced)

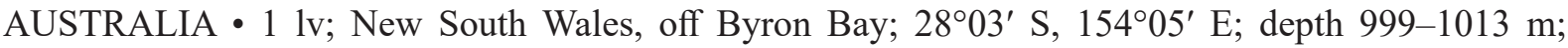
R/V Investigator, cruise IN2017_V03_100; AMS C.519344.

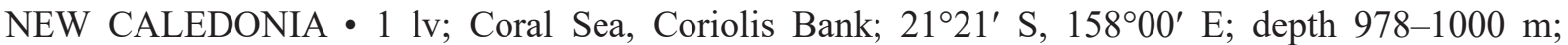
KANADEEP, stn CP4963; MNHN-IM-2013-48244 - 3 lv; Coral Sea, Coriolis Bank; $21^{\circ} 20^{\prime}$ S, 15750' E; depth $961 \mathrm{~m}$; KANADEEP, stn CP4965; MNHN-IM-2013-48144, MNHN-IM-2013-48169, MNHN-IM-2013-48258 - $2 \mathrm{lv}$; Coral Sea, Coriolis Bank; $21^{\circ} 10^{\prime} \mathrm{S}, 157^{\circ} 46^{\prime} \mathrm{E}$; depth 975-980 m; KANADEEP, stn CP4966; MNHN-IM-2013-48167, MNHN-IM-2013-48235.

SOLOMON ISLANDS • 1 lv; Sta Isabel I.; 084' S, 159³8' E; depth 762-1060 m; SALOMON 2, stn CP2182; MNHN-IM-2009-16763.

\section{Description}

MEASUREMENTs (holotype, largest specimen). SL $41.4 \mathrm{~mm}$, AL (with canal) $23.0 \mathrm{~mm}$, AL (without canal) $13.7 \mathrm{~mm}, \mathrm{SW} 12.4 \mathrm{~mm}$.

SHELL (holotype). Moderately thick, slightly glossy, strong except for fragile and partially broken outer aperture lip, narrowly fusiform, with high spire and moderately long, straight siphonal canal. Protoconch small, globose, of about 1.5 strongly convex, eroded whorls. Protoconch/teleoconch transition marked by strongly arcuate axial rib, corresponding to shape of growth lines, followed by 10 thinner and weaker axial ribs and rather thickened growth lines. Protoconch diameter $1.0 \mathrm{~mm}$, height $0.84 \mathrm{~mm}$. Spire whorls distinctly angled at shoulder, last whorl with scarcely discernible shoulder. Total teleoconch whorls just over 8. Suture shallowly impressed, subsutural ramp broad, concave, on last whorl weakly concave. Subsutural region with a row of distinct, dense, narrow, short, prosocline axial wrinkles, corresponding to upper parts of thickened growth lines, extending from suture to upper $1 / 3$ of ramp, increasing in number from 22 on first whorl to 42 on penultimate and 50 on last whorl. Shoulder of teleoconch whorls (except last one) with a row of distinct opisthoclinely elongated nodules, extending to abapical suture and intersected by spiral cords, increasing in number from 13 on first whorl to 21 on antepenultimate and penultimate whorls. Subsutural ramp smooth except for axial wrinkles mentioned above. Spiral cords intersecting shoulder nodules beginning on $2^{\text {rd }}$ teleoconch whorls (due to corrosion of shell their number is unclear) and becoming progressively stronger, 7 on antepenultimate and 8 on penultimate whorl. Cords closely spaced with intervals about half the width of cords. On last whorl cords covering entire shell surface below indistinct shoulder, about 40 cords in total, of which 20 on canal. Cords weak, slightly wavy, very closely spaced just below suture and with intervals $0.5-1.0$ times cord width on shell base and canal. Shell base gradually narrowing towards narrow, nearly straight siphonal canal. Aperture narrow, constricted posteriorly, with narrow, moderately thick parietal callus, outer lip partially broken, evenly convex and weakly concave at transition to canal. Anal sinus shallow, subsutural, broadly arcuate, confluent with large forward extension of outer lip as deduced from growth lines. Shell off-white, with 

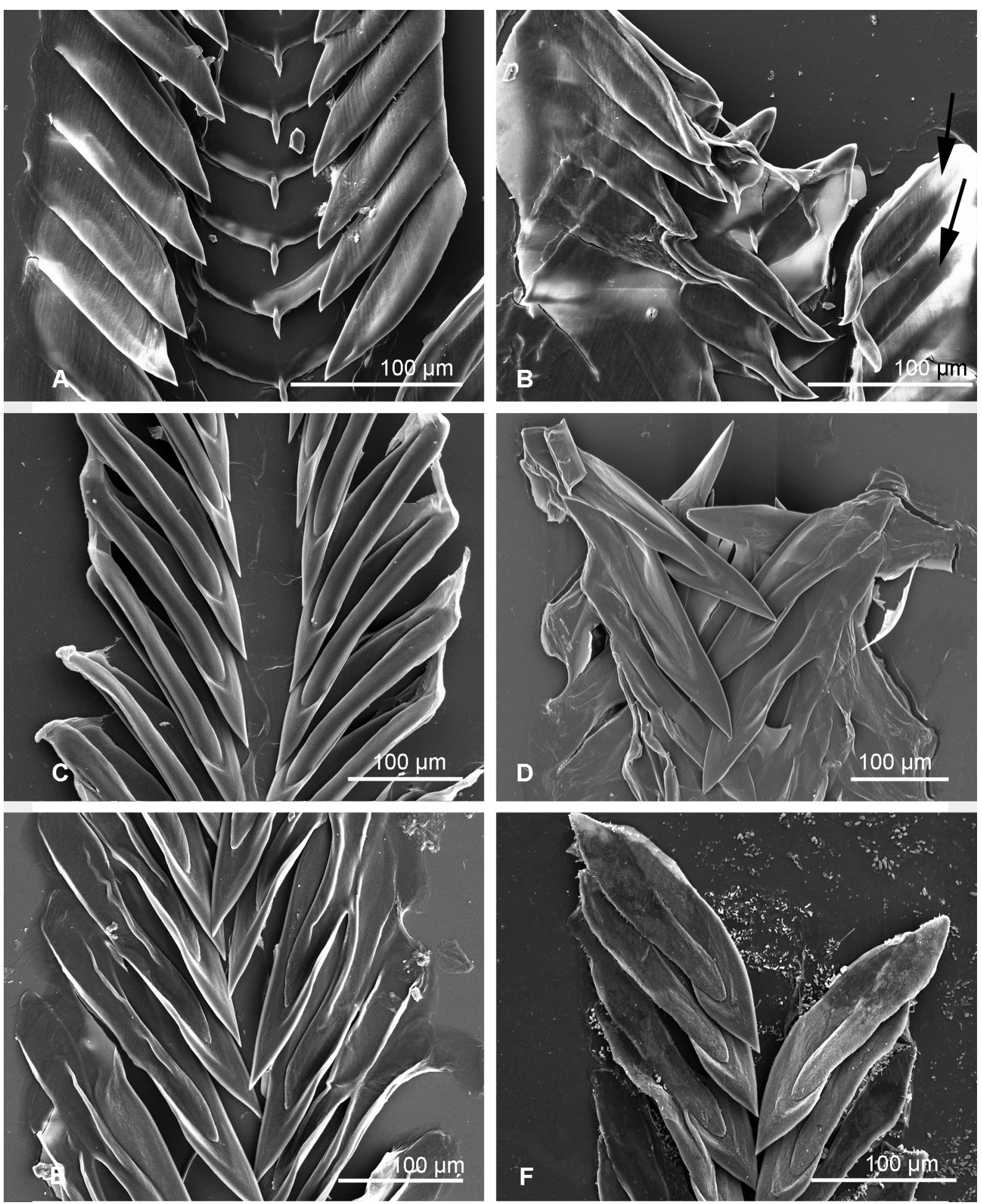

Fig. 11. Radulae of species of Sibogasyrinx Powell, 1969 and Leucosyrinx Dall, 1889. A-B. Sibogasyrinx clausura sp. nov., MNHN-IM-2009-16763. A. Central part of radula with fully formed teeth. B. Anteriormost part of radula at bending plane; marginal teeth at the right (black arrows) are unfolded due to mechanical impact. C. Leucosyrinx verrillii (Dall, 1881), French Guiana, MNHN-IM-2013-56288 (shell seen on Fig. 13C). D. Leucosyrinx sp. F, Coral Sea, MNHN-IM-2007-17846 (shell seen on Fig. 13K). E. Leucosyrinx sp. G, Papua New Guinea, MNHN-IM-2009-17089 (shell seen on Fig. 13D). F. Leucosyrinx sp. C, Solomon Islands, MNHN-IM-2007-42503 (shell seen on Fig. 13J). 
slightly darker subsutural ramp, protoconch light tan. Periostracum smooth, retained between cords and ribs.

Anatomy ( $\mathrm{n}=1$; MNHN-IM-2009-16763). Male. Penis obliquely truncated at tip with short, large, conical papilla occupying entire anterior part of penis, surrounded by circular fold. Eyes present. Proboscis moderately long, conical, with expanded base. Proboscis retractors not defined, entire posterior part of proboscis base muscular. Salivary glands small, not fused, with very long ducts that run within walls of oesophagus. Buccal mass moderately large, about $1 / 3$ of proboscis length, basal, protruding backwards beyond proboscis base, radular sac lying outside proboscis. Venom gland very large, thick and strongly convoluted, very constricted before opening into oesophagus in region of nerve ring. Muscular bulb moderately large.

RAdULA ( $\mathrm{n}=1$; MNHN-IM-2009-16763, AL 10.6 mm) (Fig. 11A-B). Relatively short, comprising 38 rows of teeth, 16 nascent. Radula length $1.65 \mathrm{~mm}$ (15.5\% of AL without canal), width up to $250 \mu \mathrm{m}$ ( $2.35 \%$ of AL without canal). Central tooth with basal plate, having distinct anterior and lateral borders and long, narrow, sharply-pointed cusp. Anterior margin overlapped by preceding row, posterior margin almost evenly rounded except for narrow protrusion adjoining cusp. Marginal teeth flat when formed, becoming trough-shaped with weakly thickened edges during maturation, folded longitudinally when fully formed, with both margins overlapping at tooth tip. The resulting folded tooth is moderately broad with a sharp pointed tip, border between margins appears as a narrow groove along anterior edge. Tooth folding occurs within $15-16^{\text {th }}$ row of teeth (counting from rear).

\section{Remarks}

The other specimens are very similar to the holotype in shell shape and sculpture. In some specimens there is very indistinct spiral striation on the subsutural ramp and a single very weak spiral cord may even be present.

This species is most similar to Sibogasyrinx maximei sp. nov., but differs in having more numerous and narrower subsutural axial wrinkles (50 vs 43 on last whorl and 42 vs 34 on penultimate one) and less numerous (40 vs 50) spiral cords on the last whorl, the holotypes of both species being of almost the same size. Nevertheless, $S$. maximei sp. nov. is only represented in our material by a single specimen and thus its intraspecific variability remains unknown. The two species are broadly sympatric in the Solomon Islands, but are clearly differentiated in our molecular analysis.

\section{Distribution}

This species occurs in the Solomon Islands, New South Wales and on the Coriolis Bank in the Coral Sea, at $762-1060 \mathrm{~m}$. This bathymetric range corresponds to a single haul in the Solomon Islands, while all other specimens were collected at 960-1000 m, indicating a narrower bathymetric range for the species.

Sibogasyrinx pagodiformis sp. nov. (= $\mathrm{PSH} 5)$

urn:lsid:zoobank.org:act:DAA613D6-5AB6-4F89-A0AD-0C718A60307E

Figs $8 \mathrm{~F}, 12 \mathrm{~A}-\mathrm{D}$

\section{Diagnosis}

Shell small, reaching $29 \mathrm{~mm}$ in length, pagodiform, with strongly concave subsutural ramp bearing two low spiral cords and distinct subsutural nodules. Axial sculpture of distinct opisthocline ribs extending to shell base, 10-11 per whorl. Spiral sculpture of closely spaced cords on and below shoulder. Radula lacking central tooth, marginal teeth trough-shaped with thickened edges. 


\section{Etymology}

The name reflects the characteristic shell shape, resembling a pagoda.

\section{Material examined}

Holotype

SOLOMON ISLANDS • NW of Malaita I.; $08^{\circ} 28^{\prime} \mathrm{S}, 160^{\circ} 32^{\prime} \mathrm{E}$; depth 1250-1402 m; SALOMONBOA 3, stn CP2789; MNHN-IM-2009-16825.

Other material (sequenced)

VANUATU • 1 lv; E of Malekula I.; $16^{\circ} 00^{\prime} \mathrm{S}, 167^{\circ} 38^{\prime} \mathrm{E}$; depth 1262-1285 m; SANTO 2006, stn AT139; MNHN-IM-2009-11327.

\section{Description}

MEASUREMENTS (holotype). SL $28.8 \mathrm{~mm}$, AL (with canal) $15.2 \mathrm{~mm}$, AL (without canal) $9.9 \mathrm{~mm}, \mathrm{SW}$ $11.9 \mathrm{~mm}$.

SHELL (holotype). Moderately thick, except for fragile, partially chipped outer aperture lip; pagodiform, with moderately high spire and moderately long, narrow siphonal canal inclined to abaxially left. Protoconch missing (rendering exact an whorl count and protoconch measurements impossible), upper teleoconch whorls eroded. Teleoconch whorls rapidly increasing and strongly angled at shoulder, more than 8 remaining. Suture shallowly impressed, subsutural ramp broad, concave. A row of distinct, sharp, subsutural nodules on upper teleoconch whorls. Nodules less distinct on last three whorls and situated on short, slightly raised, prosocline axial ribs. Number of ribs on uppermost whorls indeterminate due to shell surface erosion, number of nodules per whorl increasing from 16-17 on first intact whorl to 22 on penultimate and 26 on last whorl. Subsutural ramp smooth except for nodules and two low, indistinct subsutural cords. Shoulder with pronounced, thickened, opisthocline axial ribs on all teleoconch whorls. Axial ribs on upper teleoconch whorls situated just above suture, extending to shell base on last whorl, number of ribs constant, 11-12 per whorl. Ribs intersected by closely spaced, rounded spiral cords, number increasing from 5 on uppermost remaining whorl to 10 on penultimate whorl. Last whorl with total of 38 cords, including 18 on canal. Cords narrow, their intervals $0.5-1.5$ times cord width. Shell base rapidly narrowing towards narrow, moderately long siphonal canal. Aperture narrow, constricted posteriorly, with thin, moderately broad parietal callus, outer lip partially broken, convex on subsutural ramp, with rounded angle at shoulder, convex below shoulder and weakly concave at transition to canal. Anal sinus judging from growth lines shallow, subsutural, broadly arcuate. Shell flesh-coloured, with darker base, glossy. Periostracum thin, persisting in some cord intervals.

Anatomy ( $\mathrm{n}=1$; MNHN-IM-2009-11327). Female. Proboscis relatively short, straight, cylindrical. Proboscis retractors large, in two bundles attached at proboscis base. Buccal mass within proboscis, rather long, about half length of proboscis, radular sac opening on right. Venom gland very thick, not long, opening with very short constriction just posterior to nerve ring. Venom bulb moderately large, elongate.

RADULA ( $\mathrm{n}=2$; MNHN-IM-2009-16825, AL 9.9 mm, IM-2009-11327, AL ca 9 mm). Relatively short, comprising 20-24 rows of teeth, 8-9 nascent. Radula length $1.1-1.6 \mathrm{~mm}$ (12-16\% of AL without canal), tooth length $150 \mu \mathrm{m}$ (1.7\% of AL without canal). Central tooth absent. Marginal teeth trough-shaped when mature (Fig. 8F), with slightly thickened edges and sharp pointed tips. Teeth initially forming as a flat, elongate-oval plate, its edges gradually thickening along radular membrane and then by longitudinal folding of each tooth on $10-11^{\text {th }}$ row, counting from rear.

\section{Remarks}

The second live collected specimen has a broken shell base. In sculpture pattern it is very similar to the holotype. 
The species is distinct from all congeners in having a relatively broad, pagodiform shell with a shorter canal. Conchologically the species is quite similar to Comitas paupera (Watson, 1881), a highly variable species of uncertain generic affinity, but differing in lacking distinct spiral cords on the subsutural ramp.

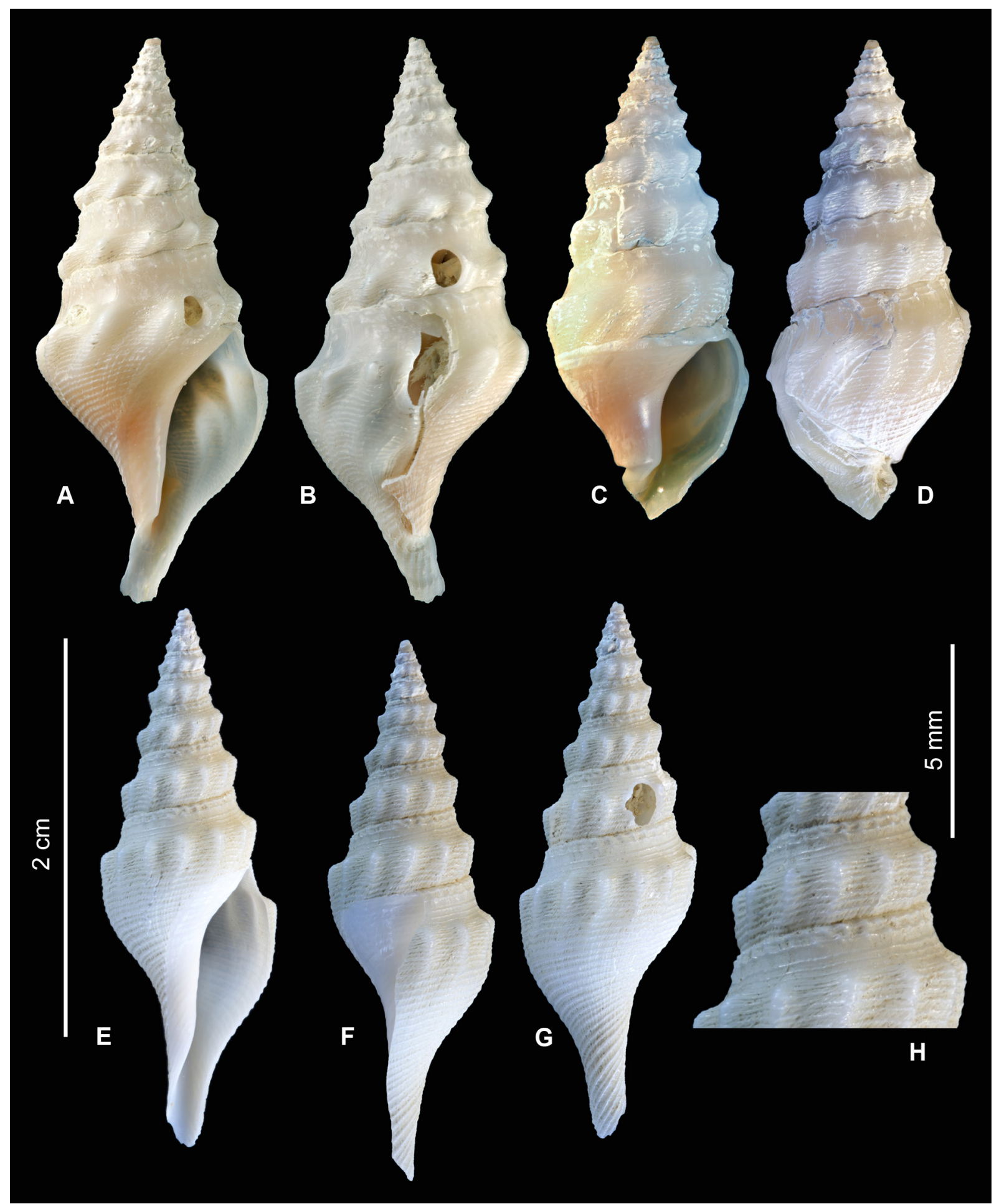

Fig. 12. A-D. Sibogasyrinx pagodiformis sp. nov. A-B. Solomon Islands, holotype, MNHNIM-2009-16825, SL 28.8 mm. C-D. Vanuatu. MNHN-IM-2009-11327, SL 24.3 mm. E-H. Sibogasyrinx elbakyanae Kantor, Puillandre \& Bouchet sp. nov., holotype, Solomon Islands, MNHN-IM-2009-16834, SL $27.3 \mathrm{~mm}$. H. Enlarged fragment of penultimate and antepenultimate whorls. A-G to same scale. 
The lectotype and paralectotypes of the latter were illustrated by Sysoev (1996: figs 42-48). Superficially, the new species also strongly resembles a miniature copy of Leucosyrinx luzonica (Powell, 1969) (see Kantor et al. 2018: fig. 21), but differs in the shape of the marginal radular teeth and foregut anatomy. Another species of Leucosyrinx from the Solomon Islands, Leucosyrinx sp. D, is similar to the new species in shell outline (Fig. 13F), differing in radular morphology.

\section{Distribution}

This species was found in the Solomon Islands and Vanuatu at 1250-1262 m.

Sibogasyrinx elbakyanae Kantor, Puillandre \& Bouchet sp. nov. (= PSH 4)
urn:lsid:zoobank.org:act:F9B671D9-4F84-4DF4-BAA0-3EF30AF06512

Fig. 12E-H

\section{Diagnosis}

Shell small, reaching $27.5 \mathrm{~mm}$ in length, fusiform, subsutural ramp strongly concave with distinct, broadly-spaced spiral cords and dense subsutural nodules. Axial sculpture of distinct opisthocline ribs extending to shell periphery. Spiral sculpture of distinct cords on and below shoulder.

\section{Etymology}

Philippe Bouchet joins us in dedicating this species to honor Alexandra Elbakyan, creator of the famous sci-hub portal.

\section{Material examined}

\section{Holotype}

SOLOMON ISLANDS • S of Malaita I.; 09 $55^{\prime}$ S, 161³3' E; depth 1136-1750 m; SALOMONBOA 3, stn CP2817; MNHN-IM-2009-16834.

\section{Description (holotype)}

MeAsurements. SL $27.3 \mathrm{~mm}$, AL (with canal) $15.0 \mathrm{~mm}$, AL (without canal) $9.6 \mathrm{~mm}$, SW $8.9 \mathrm{~mm}$.

SHELL. Moderately thick, except for fragile outer aperture lip, partially chipped; fusiform, with high spire and long, narrow, straight siphonal canal. Protoconch eroded and partially decollated, thus rendering whorl count and measurements impossible. Teleoconch whorls strongly angled at shoulder, about 8 whorls in total. Suture deeply impressed, subsutural ramp moderately broad, strongly concave. Subsutural region with a row of dense, distinct, sigmoidal axial ribs that correspond in shape to upper parts of thickened growth lines and form small rounded nodules at intersections with spiral cords. Rib counts on uppermost whorls not possible due to shell surface erosion, about 24 on antepenultimate whorl, 27 on penultimate and 34 on last whorl. Subsutural ramp with thin but distinct spiral cords, 3 on first preserved teleoconch whorl and 5 on last three whorls, one immediately subsutural followed by another with interval about three times cord width, then three more closely spaced ones separated from second cord by an interval of about five times cord width. Upper two cords forming nodules at intersections with axial ribs. Shoulder with pronounced, thickened, opisthocline axial ribs on all teleoconch whorls, about 12 on upper whorls, including penultimate one and 14 on last whorl. Ribs extending to abapical suture on spire whorls, intersected by spiral cords, uppermost $2-3$ very thin and closely spaced followed by 5-8 more broadly spaced. Last whorl with about 35 cords on shoulder and below, including 15 on canal. Cords narrow and separated by intervals 1-3 times the width of cords on axial ribs on shoulder, more broadly spaced on shell base and canal. Shell base gradually narrowing towards narrow, moderately long, nearly straight siphonal canal. Aperture narrow, constricted posteriorly, with moderately broad, thin parietal callus, outer lip partially broken, with rounded angle at shoulder, weakly convex below 
shoulder and weakly concave at transition to canal. Anal sinus shallow, subsutural, broadly arcuate. Shell base off-white, upper part of last whorl and teleoconch whorls very light yellow. Periostracum thin, persisting in intervals between cords and ribs.

ANATOMY. Adult male, penis long, gradually narrowing towards tip, obliquely truncated at tip with a small but rather long conical papilla, surrounded by circular fold. Proboscis not long, conical, proboscis retractors not defined, entire posterior part of proboscis base muscular. Salivary glands fused, small. Single oval accessory salivary gland present at level of anterior part of proboscis. Venom gland large, thick and strongly convoluted, very constricted before opening into oesophagus within nerve ring. Muscular bulb moderately large.

RADULA. Minute, comprising about 15 rows of teeth. Radula length $650 \mu \mathrm{m}$ ( $6.8 \%$ of AL without canal), width up to $100 \mu \mathrm{m}$ ( $1 \%$ of AL without canal). Central tooth present, with long cusp. Marginal teeth trough-shaped. Due to poor preparation it was impossible to study tooth morphology in detail.

\section{Remarks}

This species is most similar to Sibogasyrinx filosa, but differs in having a more stout shell with a relatively shorter canal, fewer, more distinct axial ribs on the shoulder (35 vs 46 on last whorl), and thinner, more widely spaced spiral cords. In shell outline the new species resembles some species of Leucosyrinx, particularly Leucosyrinx verrillii (Dall, 1881) (Fig. 13A-C), but differs in its smaller size, less numerous shoulder nodules and radular morphology.

\section{Distribution}

Known only from the type locality.

\section{Discussion}

Conchologically, the species of Sibogasyrinx described herein are rather heterogeneous on one hand, while on the other, some species are very similar to each other (e.g. S. cf. pyramidalis 1 and $S$. cf. pyramidalis 2; S. filosa and S. lolae sp. nov.). Furthermore, species of Sibogasyrinx are superficially similar in shell shape and sculpture to species of Leucosyrinx (Fig. 13); thus, based on shell alone, it is not possible to reliably attribute the species to either genus. Comparisons of species of Sibogasyrinx with similar species of Leucosyrinx (still mostly undescribed) are provided in the remark sections. This similarity in shell morphology between unrelated genera suggests that additional species of Sibogasyrinx may be found among taxa that are presently, but incorrectly, classified within Leucosyrinx. Whether the occurrence of similar shells in taxa that potentially diverged more than 130 mya (Abdelkrim et al. 2018) is linked to the retention of ancestral state characters or to convergence remains to be determined.

Anatomically, species of Sibogasyrinx are rather variable interspecifically, particularly with regard to radula characters. Three radula types were observed within the species of this genus, which is uncommon for Conoidea, where intrageneric variation in radula form is generally limited. Two of these types are confined to highly supported subclades within Sibogasyrinx. The Type 1 of radula is found in $S$. cf. pyramidalis 1 and 2 and $S$. subula sp. nov. (Fig. 4). Here, fully matured marginal teeth are similar to duplex teeth found in different families of Conoidea (e.g., in Turridae and some Pseudomelatomidae, including Leucosyrinx; Fig. 11C-F). The developing teeth in the younger, posterior part of the membrane (Fig. 4A) are trough-shaped, with the anterior edge (Fig. 4A, ae) of the tooth poorly sclerotized and attached to the membrane, while the posterior edge (Fig. 4A, pe) becomes progressively thicker along the membrane, lifting from the membrane and drawing closer to the anterior edge, thus making the tooth fold longitudinally. The fully formed and immature marginal teeth in the same radula membrane look markedly different (compare Fig. 4A and 4B). In this radula type, the central teeth are well developed. 


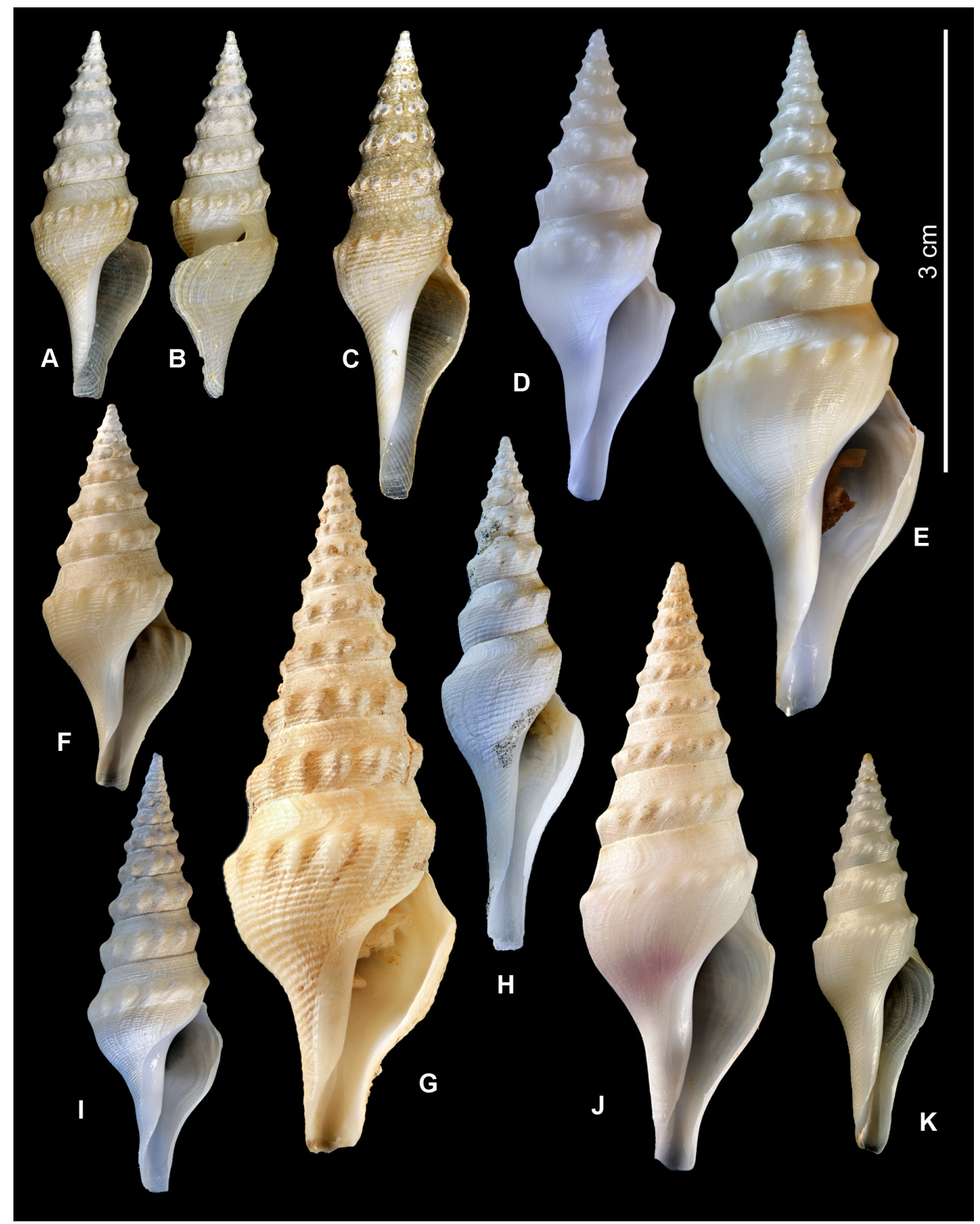

Fig. 13. Shells of species of Leucosyrinx Dall, 1889. A-B. Leucosyrinx verrillii (Dall, 1881), French Guiana, MNHN-IM-2013-56840, SL 25.1 mm. C. L. verrillii, French Guiana, MNHN-IM-2013-56288, SL $31.9 \mathrm{~mm}$ (radula seen on Fig. 11C). D-E. Leucosyrinx sp. G. D. Papua New Guinea, MNHNIM-2009-17089, SL 32.2 mm (radula seen on Fig. 11E). E. Bismarck Sea, MNHN-IM-2013-19689, SL47.3 mm. F. Leucosyrinx sp. D, Solomon Islands, MNHN-IM-2009-16769, SL 25 mm. G. Leucosyrinx sp. E, Madagascar, MNHN-IM-2009-16897, SL 46.1 mm. H. Leucosyrinx sp. A, Philippines, MNHNIM-2007-42445, SL 34.1 mm. I. Leucosyrinx sp. B, Solomon Islands, MNHN IM-2009-16764, SL 29.9 mm. J. Leucosyrinx sp. C, Solomon Islands, MNHN-IM-2007-42503, SL $41.2 \mathrm{~mm}$ (radula seen on Fig. 11F). K. Leucosyrinx sp. F, Coral Sea, Chesterfield Plateau, MNHN-IM-2007-17846, SL 27.3 mm (radula seen on Fig. 11D). All shells to same scale. 
The Type 2 of radula is recorded in several species forming a well-supported clade: Sibogasyrinx sangeri, S. filosa, S. lolae sp. nov., S. maximei sp. nov. and S. clausura sp. nov. While the central teeth are well developed and similar in shape to the teeth of the first radula type, the marginal teeth are markedly different and so far appear to be unique within the Conoidea (Figs 8A-E, 11A-B). When formed and during maturation the teeth transform from the initial flat plates, to trough-shaped plates with a weakly thickened anterior edge (Fig. 8B, ae) and a not thickened posterior edge (Fig. 8B, pe). Then, mid-way along the membrane, the teeth are abruptly folded longitudinally. The resulting folded tooth (Fig. 8A) is moderately broad (half the width of the original unfolded plate) with a sharply pointed tip. The border between both edges is evident as a narrow slit along the anterior margin of the tooth. Although this folded pattern of the marginal teeth is rather stable and evidently remains unchanged in most of the radulae studied, the teeth may become unfolded due to mechanical impact (on Fig. 11B such an unfolded tooth on the working part of the membrane is marked by a black arrow).

Finally, the Type 3 of radula was found in Sibogasyrinx pagodiformis sp. nov. (Fig. 8F). Here the marginal teeth are more similar to those of radula type 1, with a more thickened posterior edge, although they retain a clear trough shape when fully formed. The central teeth are absent, which is unique for Cochlespiridae in general and Sibogasyrinx in particular.

Sibogasyrinx pagodiformis sp. nov. has a broad, pagodiform shell, which is rather atypical for the genus. Nevertheless, its position in Sibogasyrinx is confirmed both by molecular data and the anatomy of the anterior foregut. The venom gland in this species opens into the oesophagus just posterior to the nerve ring, as in the other species of Sibogasyrinx examined (this character is a symplesiomorphy of the Cochlespiridae; Abdelkrim et al. 2018), while in other families of Conoidea the venom gland passes through the nerve ring (with a significant part of its length situated anterior to the ring) and inserts just posterior to the radular sac.

The foregut anatomy is similar in the other species of Sibogasyrinx studied (Fig. 5), differing only in minor details, such as the arrangement of the proboscis retractors (well defined, grouped in two lateral bundles attached to the most posterior part of the proboscis sheath in S. pagodiformis sp. nov., S. lolae sp. nov., $S$. subula sp. nov. and $S$. cf. pyramidalis, or absent as in $S$. elbakyanae sp. nov., S. clausura sp. nov., $S$. filosa). The buccal mass is usually situated posterior to the proboscis, but may be partially (S. clausura sp. nov.) or completely (e.g., S. lolae sp. nov.) contained within the proboscis. The salivary glands may be separate or fused. An accessory salivary gland was found in Sibogasyrinx cf. pyramidalis 1 and $S$. lolae sp. nov., but this structure is difficult to observe during manual dissection and it may be present in some other species as well.

Eyes may be present (S. filosa, S. clausura sp. nov.) or absent (S. cf. pyramidalis, S. subula sp. nov.), and this showed no relation to the bathymetric range of the species.

Presently, species of Sibogasyrinx are known only from the central West Pacific - from the South China Sea and the Philippines to Indonesia (type species, S. pyramidalis) and south to Vanuatu, New Caledonia and Australia. Despite a number of cruises led by MNHN at appropriate depths in the Indian Ocean, as well as in Fiji, Tonga and French Polynesia, Sibogasyrinx was not recorded there, as well as in Japan despite adequate sampling effort in that region. The genus is most diverse off the Solomon Islands (8 species recorded) and Papua New Guinea (4 species), but it is not clear at present whether this is a result of more intense sampling in these areas or a genuine distributional feature. The species are confined to the upper bathyal $(300-800 \mathrm{~m})$ with a few species penetrating the upper portion of the lower bathyal $(800-2000 \mathrm{~m})$. Only one species (S. filosa) was recorded as shallow as $150 \mathrm{~m}$, but it also extends to $1100 \mathrm{~m}$ (508 $\mathrm{m}$ as confirmed by molecular data). For species that are represented by numerous samples, the bathymetric range is rather large, spanning several hundred meters, although, as mentioned earlier, some species seem to have more limited bathymetric ranges. 


\section{Acknowledgments}

Specimens were obtained during research cruises and expeditions organized by the MNHN and ProNatura International as part of the Our Planet Reviewed program, and by the MNHN and the Institut de Recherche pour le Développement as part of the Tropical Deep-Sea Benthos program (DongSha 2014 and NanHai 2014 in the South China Sea; AURORA 2007 and PANGLAO 2005 in the Philippines; SALOMON 2 and SALOMONBOA 3 in the Solomon Islands; BIOPAPUA, KAVIENG 2014, MADEEP and PAPUA NIUGINI in Papua New Guinea; BOA1 and SANTO 2006 in Vanuatu; EXBODI, KANADEEP and TERRASSES in New Caledonia; EBISCO in the Chesterfield Islands; MIRIKY in Madagascar; GUYANE 2014 in French Guiana), and we are grateful to numerous cruise leaders and co-PIs: Wei-Jen Chen, Philippe Bouchet, Marivene Manuel Santos, Laure Corbari, Stephane Hourdez, Ludivina Labe, Peter Kee Lin Ng, Karine Olu-Le Roy, Bertrand Richer de Forges and Sarah Samadi. All expeditions operated under the regulations then in force in the countries in question and satisfy the conditions set by the Nagoya Protocol for access to genetic resources. We thank Francesco Criscione and Anders Halan for providing additional material from the Australian Museum. The authors thank Virginie Héros, Barbara Buge, Philippe Maestrati, Julien Brisset (MNHN) and Alexander Fedosov (IEE RAS) for their help in curating the vouchers and the associated data. Dr Roberto Ardovini kindly provided the photos of the holotype of Sibogasyrinx filosa. The photos of the holotype of Surcula pyramidalis were provided by Jeroen Goud (Naturalis Biodiversity Center) and Dr Kazunori Hasegawa. We thank Elena Mekhova from IEE RAS for assisting with shell photography. Our special thanks to Dr David Herbert, who edited and corrected the manuscript, as well as Dr Philippe Bouchet and Dr Alexander Fedosov for constructive reviews.

This study was conducted using Joint Usage Center "Instrumental methods in ecology" at the IEE RAS. We thank A. Neretina and A. Nekrasov for their friendly and helpful assistance with the SEM facilities.

The project has received funding from the European Research Council (ERC) under the European Union's Horizon 2020 research and innovation programme (grant agreement no. 865101) to NP.

\section{References}

Abdelkrim J., Aznar-Cormano L., Fedosov A., Kantor Y.I., Lozouet P., Phuong M., Zaharias P. \& Puillandre N. 2018. Exon-capture based phylogeny and diversification of the venomous gastropods (Neogastropoda, Conoidea). Molecular Biology and Evolution 35 (10): 2355-2374.

https://doi.org/10.1093/molbev/msy144

Ardovini R. 2021. Descrizione di Sibogasyrinx filosus n.sp. (Neogastropoda, Conoidea, Cochlespiridae) da Papua Nuova Guinea, Oceano Pacifico Meridionale. Malacologia Mostra Mondiale 111: 5-6.

Bouchet P. \& Kantor Y.I. 2004. New Caledonia: the major centre of biodiversity for volutomitrid molluscs (Mollusca: Neogastropoda: Volutomitridae). Systematics and Biodiversity 1 (4): 467-502. https://doi.org/10.1017/S1477200003001282

Bouchet P., Kantor Y.I., Sysoev A. \& Puillandre N. 2011. New operational classification of the Conoidea (Gastropoda). Journal of Molluscan Studies 77: 273-308. https://doi.org/10.1093/mollus/eyr017

Folmer O., Black M., Hoeh W., Lutz R. \& Vrijenhoek R. 1994. DNA primers for amplification of mitochondrial cytochrome c oxidase subunit I from diverse metazoan invertebrates. Molecular Marine Biology and Biotechnology 3: 294-299.

Galindo L.A., Puillandre N., Strong E.E. \& Bouchet P. 2014. Using microwaves to prepare gastropods for DNA barcoding. Molecular Ecology Resources 14: 700-705. https://doi.org/10.1111/1755-0998.12231 
Kantor Y.I. \& Puillandre N. 2012. Evolution of the radular apparatus in Conoidea (Gastropoda: Neogastropoda) as inferred from a molecular phylogeny. Malacologia 55: 55-90.

Kantor Y.I., Fedosov A.E. \& Puillandre N. 2018. New and unusual deep-water Conoidea revised with shell, radula and DNA characters. Ruthenica, Russian Malacological Journal 28: 47-82.

Medinskaya A.I. 1999. Foregut anatomy of the Cochlespirinae (Gastropoda, Conoidea, Turridae). Zoosystema 21: 171-198.

Minh B.Q., Nguyen M.A.T. \& von Haeseler A. 2013. Ultrafast approximation for phylogenetic bootstrap. Molecular Biology and Evolution 30 (5): 1188-1195. https://doi.org/10.1093/molbev/mst024

Powell A.W.B. 1969. The family Turridae in the Indo-Pacific. Part 2. The subfamily Turriculinae. IndoPacific Mollusca 2 (10): 215-416. Available from https://www.biodiversitylibrary.org/page/49824050 [accessed 24 Aug. 2021].

Puillandre N., Kantor Y.I, Sysoev A., Couloux A., Meyer C., Rawlings T., Todd J.A. \& Bouchet P. 2011. The dragon tamed? A molecular phylogeny of the Conoidea (Mollusca, Gastropoda). Journal of Molluscan Studies 77 (3): 259-272. https://doi.org/10.1093/mollus/eyr015

Puillandre N., Lambert A., Brouillet S. \& Achaz G. 2012a. ABGD, Automatic Barcode Gap Discovery for primary species delimitation. Molecular Ecology 21 (8): 1864-1877.

https://doi.org/10.1111/j.1365-294X.2011.05239.x

Puillandre N., Modica M.V., Zhan Y., Sirovich L., Boisselier M.-C., Cruaud C., Holford M. \& Samadi S. 2012b. Large-scale species delimitation method for hyperdiverse groups. Molecular Ecology 21 (11): 2671-2691. https://doi.org/10.1111/j.1365-294X.2012.05559.x

Puillandre N., Fedosov A.E., Zaharias P., Aznar-Cormano L. \& Kantor Y.I. 2017. A quest for the lost types of Lophiotoma (Gastropoda: Conoidea: Turridae): integrative taxonomy in a nomenclatural mess. Zoological Journal of the Linnean Society 181 (2): 243-271. https://doi.org/10.1093/zoolinnean/zlx012

Puillandre N., Brouillet S. \& Achaz G. 2021. ASAP: assemble species by automatic partitioning. Molecular Ecology Resources 21 (2): 609-620. https://doi.org/10.1111/1755-0998.13281

Rambaut A. \& Drummond A.J. 2014. Tracer ver. 1.6. Available from http://beast.bio.ed.ac.uk/Tracer [accessed 24 Aug. 2021].

Ronquist F., Teslenko M., Van Der Mark P., Ayres D.A., Darling A., Höhna S., Larget B., Liu L., Suchard M.A. \& Huelsenbeck J.P. 2012. MrBayes 3.2: efficient Bayesian phylogenetic inference and model choice across a large model space. Systematic Biology 61 (3): 539-542.

https://doi.org/10.1093/sysbio/sys029

Schepman M.M. 1913. The Prosobranchia of the Siboga Expedition. Part 5. Toxoglossa. Siboga-Expeditie 49 (5): 365-452. Available from https://www.biodiversitylibrary.org/page/34450646 [accessed 24 Aug. 2021].

Shuto T. 1970. Taxonomical notes on the turrids of the Siboga-Collection originally described by M.M. Schepman, 1913 (part 1). Venus 28: 161-178.

Sysoev A.V. 1996. Deep-sea conoidean gastropods collected by the John Murray Expedition, 1933-34. Bulletin of the Natural History Museum of London, Zoology 62 (1): 1-30.

Available from https://www.biodiversitylibrary.org/page/41008506 [accessed 7 Sep. 2021]. 
Trifinopoulos J., Nguyen L.T., von Haeseler A. \& Minh B.Q. 2016. W-IQ-TREE: a fast online phylogenetic tool for maximum likelihood analysis. Nucleic Acids Research 44 (W1): W232-235. https://doi.org/10.1093/nar/gkw256

Manuscript received: 6 April 2021

Manuscript accepted: 2 July 2021

Published on: 28 September 2021

Topic editors: Rudy C.A.M. Jocqué, Tony Robillard

Section editor: Thierry Backeljau

Desk editor: Danny Eibye-Jacobsen

Printed versions of all papers are also deposited in the libraries of the institutes that are members of the EJT consortium: Muséum national d'histoire naturelle, Paris, France; Meise Botanic Garden, Belgium; Royal Museum for Central Africa, Tervuren, Belgium; Royal Belgian Institute of Natural Sciences, Brussels, Belgium; Natural History Museum of Denmark, Copenhagen, Denmark; Naturalis Biodiversity Center, Leiden, the Netherlands; Museo Nacional de Ciencias Naturales-CSIC, Madrid, Spain; Real Jardín Botánico de Madrid CSIC, Spain; Zoological Research Museum Alexander Koenig, Bonn, Germany; National Museum, Prague, Czech Republic. 